\title{
Target Cell-Specific Involvement of Presynaptic Mitochondria in Post-Tetanic Potentiation at Hippocampal Mossy Fiber Synapses
}

\author{
Doyun Lee, Kyu-Hee Lee, Won-Kyung Ho, and Suk-Ho Lee \\ National Research Laboratory for Cell Physiology, Department of Physiology, Seoul National University College of Medicine and Neuroscience Research \\ Institute, Seoul National University Medical Research Center, Seoul 110-799, Korea
}

\begin{abstract}
Previous studies indicate that boutons from the same axon exhibit distinct $\mathrm{Ca}^{2+}$ dynamics depending on the postsynaptic targets. Mossy fibers of hippocampal granule cells innervate synaptic targets via morphologically distinct boutons. We investigated mitochondrial involvement in the generation of post-tetanic residual $\mathrm{Ca}^{2+}\left(\mathrm{Ca}_{\text {res }}\right)$ at large and small en passant mossy fiber boutons (MFBs). Mitochondria limited the $\left[\mathrm{Ca}^{2+}\right]_{i}$ build-up during high-frequency stimulation (HFS) at large MFBs, but not at small MFBs. The amount of $\mathrm{Ca}_{\text {res }}$, quantified as a time integral of residual $\left[\mathrm{Ca}^{2+}\right]_{\mathrm{i}}$, was significantly larger at large MFBs than at small MFBs, and that at large MFBs was substantially attenuated by inhibitors of mitochondrial $\mathrm{Ca}^{2+}$ uniporter and mitochondrial $\mathrm{Na}^{+} / \mathrm{Ca}^{2+}$ exchanger (mitoNCX). In contrast, blockers of mitoNCX had no effect on the $\mathrm{Ca}_{\text {res }}$ at small MFBs. Post-tetanic $\mathrm{Ca}_{\text {res }}$ has been proposed as a mechanism for post-tetanic potentiation (PTP). We examined mitochondrial involvement in PTP at mossy fiber synapses on hilar mossy cells (MF $\rightarrow$ MC synapse) and on hilar interneurons ( $\mathrm{MF} \rightarrow \mathrm{HI}$ synapse), which are presumably innervated via large and small MFBs, respectively. Consistent with the differential contribution of mitochondria to $\mathrm{Ca}_{\text {res }}$ at large and small MFBs, mitoNCX blockers significantly reduced the PTP at the $\mathrm{MF} \rightarrow \mathrm{MC}$ synapse, but not at the MF $\rightarrow \mathrm{HI}$ synapse. In contrast, protein kinase $\mathrm{C}(\mathrm{PKC})$ inhibitors significantly reduced the PTP at $\mathrm{MF} \rightarrow \mathrm{HI}$ synapse, but not at the MF $\rightarrow \mathrm{MC}$ synapse. These results indicate that mitochondria- and PKC-dependent PTP are expressed at distinct hilar mossy fiber synapses depending on postsynaptic targets.
\end{abstract}

Key words: post-tetanic potentiation; residual calcium; mitochondria; hippocampal mossy fiber; hilar mossy cell; hilar interneuron

\section{Introduction}

Short-term plasticity is supposed to play a crucial role in synaptic computation (Abbott and Regehr, 2004). The hippocampal mossy fiber (MF) synapse exhibits high failure rate at resting firing frequency of granule cells (GCs), but high frequency stimulation (HFS) can induce a plastic change with wide dynamic range (Salin et al., 1996; Mori et al., 2007). Previous studies indicate that presynaptic facilitation is prerequisite for reliable transmission at MF synapse, and now MF synapses are regarded as "conditional detonator" (Henze et al., 2002; Mori et al., 2004; Bischofberger et al., 2006). Computational events occurring at MF synapses could be better understood in light of knowledge about presynaptic mechanisms underlying short-term enhancement of MF synaptic activity such as frequency facilitation and post-tetanic potentiation (PTP).

A post-tetanic elevation of presynaptic $\left[\mathrm{Ca}^{2+}\right]_{\mathrm{i}}$ lasting for tens of seconds, referred to as post-tetanic residual $\mathrm{Ca}^{2+}\left(\mathrm{Ca}_{\text {res }}\right)$, has

Received Feb. 10, 2007; revised 0ct. 12, 2007; accepted 0ct. 22, 2007.

This work was supported by Grant M103KV010008-06K2201-00810 from Brain Research Center of the 21st Century Frontier Research Program funded by the Ministry of Science and Technology of the Republic of Korea. D.L. and K.-H.L. are postgraduate students supported by Program BK21 from the Ministry of Education.

Correspondence should be addressed to Dr. Suk-Ho Lee, Department of Physiology, Seoul National University College of Medicine, Chongno-Ku, Yongon-Dong 28, Seoul 110-799, Korea. E-mail address: leesukho@snu.ac.kr. DOI:10.1523/JNEUROSCI.3985-07.2007

Copyright $\odot 2007$ Society for Neuroscience $\quad$ 0270-6474/07/2713603-11\$15.00/0 long been suggested as a mechanism for PTP. Close correlation between PTP and $\mathrm{Ca}_{\text {res }}$ has been demonstrated at numerous synapses including neuromuscular junctions (NMJs) and MF synapses (Kamiya and Zucker, 1994; Regehr et al., 1994; Habets and Borst, 2005; Korogod et al., 2005) (for review, see Zucker and Regehr, 2002). Although mitochondrial contribution to generation of $\mathrm{Ca}_{\text {res }}$ and PTP has been demonstrated at NMJs (Tang and Zucker, 1997; Garcia-Chacon et al., 2006), there is little evidence for mitochondrial involvement at central synapses (Storozhuk et al., 2005). Instead, activation of protein kinase has been proposed as underlying mechanisms for PTP in hippocampus and cerebellum, suggesting that PTP mechanism at central synapses may be different from that at NMJs (Alle et al., 2001; Brager et al., 2003; Beierlein et al., 2007; Wierda et al., 2007).

The evidence accumulated over the last decade supports the view that short-term plasticity from the same axon is different according to the identity of postsynaptic target (for review, see Toth and McBain, 2000). At neocortical and MF synapses it has been suggested that target-cell specific presynaptic $\mathrm{Ca}^{2+}$ dynamics underlies the heterogeneity in the release probability and long-term plasticity (Rozov et al., 2001; Koester and Johnston, 2005; Pelkey et al., 2006). Dentate GCs have more than one type axon terminals, each with a distinct morphology depending on the postsynaptic target (Acsady et al., 1998), but target cell- 
specific differences in the $\mathrm{Ca}^{2+}$ dynamics at different type of hippocampal mossy fiber boutons (MFBs) have not been studied.

We investigated $\mathrm{Ca}^{2+}$ transients induced by HFS from single MFBs and compared the mitochondrial involvement in the generation of $\mathrm{Ca}_{\text {res }}$ between large and small MFBs, which presumably terminate onto hilar mossy cells and interneurons, respectively. We found that $\mathrm{Na}^{+}$-dependent $\mathrm{Ca}^{2+}$ efflux (NCE) from presynaptic mitochondria contributes to $\mathrm{Ca}_{\text {res }}$ specifically at large but not small MFBs. In agreement with our observations of presynaptic $\mathrm{Ca}^{2+}$ signals, mitochondrial NCE inhibitors reduced PTP selectively at MF synapses onto hilar mossy cells, indicating that mitochondria-dependent $\mathrm{Ca}_{\text {res }}$ is responsible for PTP specifically at synapse of large MFBs. In contrast, protein kinase C (PKC) inhibitors reduced PTP exclusively at MF synapses onto hilar interneurons (HIs).

\section{Materials and Methods}

Preparation of brain slices. Transverse hippocampal brain slices were prepared from 18- to 28-d-old Sprague Dawley rats as described previously (Lee et al., 2004) under the animal welfare guideline of Seoul National University. Rats were anesthetized with isoflurane and decapitated. Brains were chilled in ice-cold low-calcium artificial CSF (aCSF) containing the following (in mM): $124 \mathrm{NaCl}, 26 \mathrm{NaHCO}_{3}, 3.2 \mathrm{KCl}, 0.5 \mathrm{CaCl}_{2}$, $7 \mathrm{MgCl}_{2}, 1.25 \mathrm{NaH}_{2} \mathrm{PO}_{4}, 10$ glucose, $2 \mathrm{Na}$-pyruvate, 3 ascorbate, with $\mathrm{pH}$ 7.4 adjusted by saturating with carbogen $\left(95 \% \mathrm{O}_{2}, 5 \% \mathrm{CO}_{2}\right)$, and with an osmolarity of $\sim 320 \mathrm{mOsm}$. Isolated brain was glued onto the stage of a vibratome (ZERO 1; Dosaka, Kyoto, Japan), and 300- $\mu$ m-thick transverse hippocampal slices were cut and incubated at $34^{\circ} \mathrm{C}$ for $30 \mathrm{~min}$ in the same solution and thereafter maintained at room temperature until required.

Drugs. All chemicals were obtained from Sigma (St. Louis, MO), except Ru360 and Ro-31-8220 from Calbiochem (La Jolla, CA), (2S, 1'R, $\left.2^{\prime} \mathrm{R}, \quad 3^{\prime} \mathrm{R}\right)-2-\left(2^{\prime}, 3^{\prime}\right.$-dicarboxycyclopropyl) glycine (DCG-IV) and CGP37157 from Tocris (Ellisville, MO), and fluorescent dyes from Invitrogen (Eugene, OR). All inhibitor drugs including tetraphenylphosphonium $\left(\mathrm{TPP}^{+}\right)$and $\mathrm{PKC}$ inhibitors were prepared as concentrated stock $(1000 \times)$ in distilled water, except carbonylcyanide m-chlorophenylhydrazone (CCCP) and CGP37157 in DMSO, and antimycin Al and oligomycin in ethanol. Stock solutions were stored at $-20^{\circ} \mathrm{C}$, and diluted to desired concentration in aCSF just before use.

Electrophysiological recordings. For $\mathrm{Ca}^{2+}$ imaging at MFBs, whole-cell patch-clamp mode was attained on the soma of a GC under visual control using differential interference illumination in an upright microscope (BX51WI; Olympus, Tokyo, Japan) while perfusing a slice with normal aCSF (the composition is the same as low-calcium aCSF except $1.3 \mathrm{~mm}$ $\mathrm{MgCl}_{2}, 2.5 \mathrm{~mm} \mathrm{CaCl}_{2}$ and without pyruvate and ascorbate). The wholecell recordings were made using an EPC-10 amplifier (HEKA Elektronik, Lambrecht, Germany) with a pipette solution containing the following (in mM): $140 \mathrm{~K}$-gluconate, 5 di-Tris-phosphocreatin, $5 \mathrm{NaCl}, 4 \mathrm{MgATP}$, $0.4 \mathrm{Na}_{2}$ GTP, 15 HEPES, $2.5 \mathrm{Na}$-pyruvate at $\mathrm{pH} 7.3$ (adjusted with $\mathrm{KOH}$ ) together with Oregon Green 488 BAPTA-1 (OGB1) and/or Oregon Green 488 BAPTA-5N (OG5N). In most experiments, $50 \mu \mathrm{M}$ OGB1 was used unless specified. When OG5N alone was used as a $\mathrm{Ca}^{2+}$-indicator dye, $20 \mu \mathrm{M}$ Alexa Fluor 633 hydrazide was added to visualize and trace the axon fibers. Action potentials (APs) were evoked by applying depolarizing pulses from -80 to $0 \mathrm{mV}$ in a voltage-clamp mode.

For recordings of EPSC at MF synapses, whole-cell recordings were made from hilar neurons at a holding potential of $-70 \mathrm{mV}$. Patch pipettes (2-4 M $\Omega$ ) were filled with an internal solution containing the following (in mM): $120 \mathrm{~K}$-gluconate, $6 \mathrm{KCl}, 5$ di-Tris-phosphocreatin, 4 MgATP, 0.4 $\mathrm{Na}_{2}$ GTP, 15 HEPES, 10 BAPTA at pH 7.3 (adjusted with $\mathrm{KOH})$. To obtain the images of dendritic morphology, $20 \mu \mathrm{M}$ Alexa633 or Alexa488 was included in the pipette solution. Synaptic responses were evoked by extracellular stimulation techniques (100 $\mu$ s duration; 2-25 V intensity) via a voltage stimulator (MASTER-8; AMPI, Jerusalem, Israel) connected to a patch electrode filled with aCSF solution, and placed near the hilar border (Lysetskiy et al., 2005). EPSCs were evoked by applying paired pulses ( $50 \mathrm{~ms}$ interval) at $0.2 \mathrm{~Hz}$ for $3-15 \mathrm{~min}$ and then HFS $(25 \mathrm{~Hz}, 5 \mathrm{~s})$ was applied. Changes in EPSC amplitude were monitored for another 5-10 min.

To monitor series resistance, negative voltage steps $(-2 \mathrm{mV}$ from holding potential, $50 \mathrm{~ms}$ ) were applied after each evoked EPSC and the recordings were discarded whether the series resistance changed by $>20 \%$. At the end of each experiment, 1 or $2 \mu \mathrm{M}$ DCG-IV was bathapplied to confirm the mossy fiber stimulation. The EPSC data were included in the analysis only when the average EPSCs were reduced by at least $80 \%$ by DCG-IV. After each experiment dendritic images of hilar neurons were taken under a confocal microscope. All experiments were done at $32 \pm 2^{\circ} \mathrm{C}$.

Cytosolic $\mathrm{Ca}^{2+}$ measurements. $\mathrm{Ca}^{2+}$ imaging was performed using a confocal laser-scanning system (FV300; Olympus) and a $60 \times$ waterimmersion objective (numerical aperture, 0.9; LUMPlanFl/IR; Olympus). After establishing a whole-cell recording mode, a $\mathrm{Ca}^{2+}$ - indicator dye was allowed to be loaded for at least $25 \mathrm{~min}$, which provides enough time for the dye in the GC soma to be equilibrated with its axon terminals, located in the range of $100-400 \mu \mathrm{m}$ from the soma. $\mathrm{Ca}^{2+}$ transients (CaTs) evoked by a single AP were recorded in a line scan mode at 200 Hz. Fluorescence responses evoked by a HFS were imaged by scanning a small region of interest (ROI) including a bouton in XY scan mode at 1 $\mathrm{Hz}$ for $100 \mathrm{~s}$ for recording $\mathrm{Ca}_{\text {res }}$ with OGB1. Scanning time per image was $<0.2$ s. For imaging a CaT during HFS with OG5N, we scanned an ROI at $2 \mathrm{~Hz}$ for $15 \mathrm{~s}$. To minimize photo-bleaching, minimal intensity of the laser power $(<2.5 \mu \mathrm{W}$ for $488 \mathrm{~nm}$ Ar laser, $<2 \mu \mathrm{W}$ for $633 \mathrm{~nm} \mathrm{He} / \mathrm{Ne}$ laser measured under the objective) and maximal pinhole size $(300 \mu \mathrm{m})$ were used. Emission light was separated by a $630 \mathrm{~nm}$ dichroic mirror and passed 545/75 and 675/50 bandpass filters ahead of detection by photomultiplier tubes for green and red fluorescence.

In the experiments using OGB1 $\left[\mathrm{Ca}^{2+}\right]_{i}$ was calculated from background-subtracted fluorescence $(F)$ as follows:

$$
\left[\mathrm{Ca}^{2+}\right]_{i}=K_{d} \frac{F-F_{\min }}{F_{\max }-F}=K_{d} \frac{F / F_{\max }-1 / R_{f}}{1-F / F_{\max }},
$$

where $R_{\mathrm{f}}=F_{\max } / F_{\min }$, and $F_{\max }$ value was measured in situ during experiment from a plateau value in the fluorescence induced by HFS (Maravall et al., 2000). All the estimates of $\left[\mathrm{Ca}^{2+}\right]$ were presented as a difference between excursion of $\left[\mathrm{Ca}^{2+}\right]$ from its resting level $\left(\Delta\left[\mathrm{Ca}^{2+}\right]_{\mathrm{i}}\right)$. The upper bound of dynamic range $\left(R_{\mathrm{f}}\right)$ and the dissociation constant $\left(K_{\mathrm{d}}\right)$ of OGB1 were determined in vitro using intracellular solution plus $10 \mathrm{mM}$ $\mathrm{Ca}^{2+}$ or 10 mm EGTA (for $R_{\mathrm{f}}$ of OGB1) and that plus $4 \mathrm{~mm} \mathrm{~K}{ }^{+}$-EGTA and $6 \mathrm{mM} \mathrm{Ca}^{2+}$-EGTA, $\left[\mathrm{Ca}^{2+}\right]$ of which was calculated as $231 \mathrm{nM}\left(\right.$ for $\mathrm{K}_{\mathrm{d}}$ of OGB1; assuming the $K_{\mathrm{d}}$ of EGTA $=95 \mathrm{~nm}$ at $\mathrm{pH}=7.3$ ). The $K_{\mathrm{d}}$ and the upper bound value of $R_{\mathrm{f}}$ were estimated as $206 \mathrm{~nm}$ and 8.5, respectively, which are very close to the values reported by others (Maravall et al., 2000). $R_{\mathrm{f}}$ cannot be accurately determined in cytosolic environment. To determine approximate value for $R_{\mathrm{f}}$ in the cell, we whole-cell patched seven pairs of dentate GCs of similar size located at the surface of the slice with the same solutions used for in vitro calibration, and measured $F_{\text {min }}$ and $F_{\max }$ from the cytosol of different cells. The mean value for $R_{\mathrm{f}}$ was estimated as 5.9 (in the range of $4.6 \sim 6.7$ ). In the following analysis, we assumed $R_{\mathrm{f}}$ to be 6 (Sabatini et al., 2002). When $R_{\mathrm{f}}$ is in-between 6 and 8 , the uncertainty in $R_{\mathrm{f}}$ can cause errors in estimating integral of $\mathrm{Ca}_{\text {res }}$ by $<5 \%$ (Maravall et al., 2000). In addition to $R_{\mathrm{f}}$, erroneous estimation of $\mathrm{F}_{\text {max }}$ and/or incorrect assumption of $K_{\mathrm{d}}$ values of the $\mathrm{Ca}^{2+}$ indicator dye in the cytosol can cause much larger error for $\Delta\left[\mathrm{Ca}^{2+}\right]$ estimates (Maravall et al., 2000). In experiments using OG5N, $\left[\mathrm{Ca}^{2+}\right]_{\mathrm{i}}$ was estimated by assuming resting $\left[\mathrm{Ca}^{2+}\right]_{\mathrm{i}}$ of $50 \mathrm{nM}$. $K_{\mathrm{d}}$ of OG5N was taken as $50 \mu \mathrm{M}$ and $R_{\mathrm{f}}$ was taken as 50 (David et al., 1997). Because we used very low intensity of laser power for long-term scanning, a few pixels having zero value at the baseline were included in the case that bouton was located deeper than $30 \mu \mathrm{m}$. In most of experiments, we scanned boutons near the surface of a slice to minimize the calculation error.

Calculation of mitochondrial $\mathrm{Ca}^{2+}$ release. Although the decay phase of a single AP-induced $\mathrm{Ca}^{2+}$-transient was better fitted with a biexponential function than a monoexponential function by $14 \%$ (the ratio of $\chi^{2}$ values for monoexponential and biexponential fits was $1.14 \pm 0.2, n=$ 


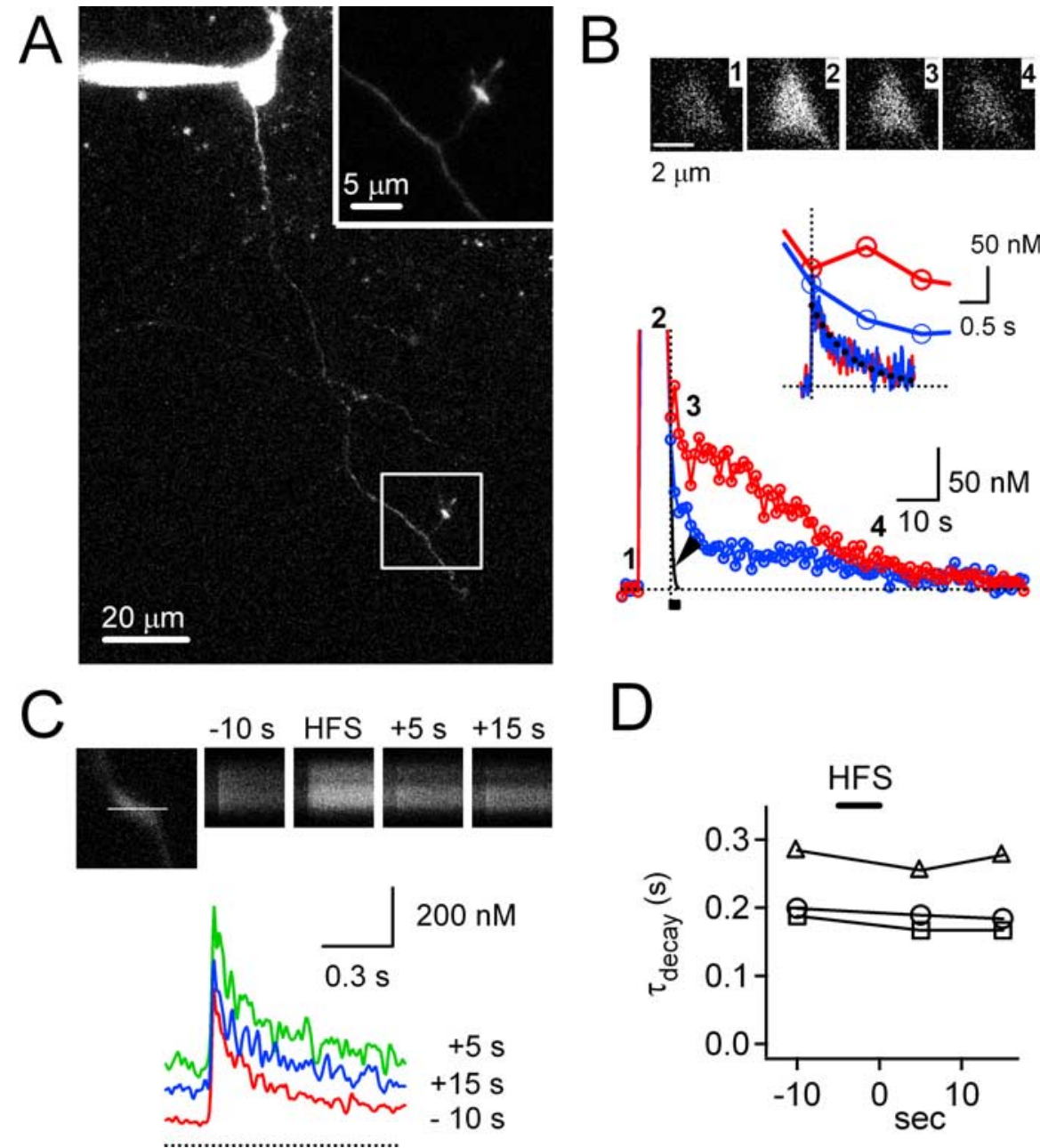

Figure 1. A representative time course of post-tetanic residual $\left[\mathrm{Ca}^{2+}\right]\left(\Delta\left[\mathrm{Ca}^{2+}\right]_{\mathrm{res}}\right)$ at the large MFB. $A, A z$-stack projection of laser-scanned images obtained from a dentate $\mathrm{GC}$ loaded with $50 \mu \mathrm{M} 0 \mathrm{~GB} 1$ via a whole-cell patch pipette on the soma. The fluorescence image shows axon collaterals and MFBs. The boxed area is shown at higher magnification in the inset. $\mathbf{B}, \mathrm{Ca}^{2+}$ transients were evoked by TS ( $33 \mathrm{~Hz}$ for $5 \mathrm{~s}$ ). Background-subtracted fluorescence in a region of interest encompassing an MFB was averaged, converted into $\left[\mathrm{Ca}^{2+}\right]_{i}$ and plotted as a function of time. Red and blue lines indicate the time courses of $\left[\mathrm{Ca}^{2+}\right]_{i}$ recorded before and after application of $2 \mu \mathrm{M}$ TPP ${ }^{+}$, respectively (same traces used in Fig. $5 \mathrm{Aa}$ ). Raw images numbered from 1 to 4 correspond to the indicated time points on the red trace. The part of the TS-CaTs indicated by the horizontal bar is shown on expanded time scale (inset, thick lines), on which single AP-CaTs obtained from the same MFB are superimposed (noisy traces; red, in control conditions; blue, in the presence of TPP $\left.{ }^{+}\right)$. To compare areas under the AP-CaT and $\Delta\left[\mathrm{Ca}^{2+}\right]_{\text {res, }}$ a monoexponential fit $\left(\tau^{-1}=386 \mathrm{~ms}\right)$ to the AP-CaTs was superimposed on $\boldsymbol{B}$, with the AP-CaT peak aligned at $t=0$ (arrowhead). The vertical dotted line indicates the time point at $t=0$. C, AP-CaTs were evoked before and after TS ( $33 \mathrm{~Hz}$ for $5 \mathrm{~s}$ ). The bouton image and line scan images at the indicated time points are shown (top). The white line $(5 \mu \mathrm{m})$ in the bouton image represents a scan line. Background-subtracted fluorescence $(\Delta F)$ transients evoked by single APs were converted to $\mathrm{Ca}^{2+}$ transients (CaTs), and superimposed (red, $10 \mathrm{~s}$ before TS; green, $5 \mathrm{~s}$ after TS; blue, $15 \mathrm{~s}$ after TS). The horizontal dotted line indicates the zero $\Delta\left[\mathrm{Ca}^{2+}\right]_{\mathrm{i}}$ level. $D$, Decay time constants of these AP-CaTs were plotted as a function of whole-cell recording time (open triangles). The time at the end of TS was set as $t=0$. Time constants obtained from other two MFBs were superimposed with different markers.

13), we assumed that (1) an MFB is a single compartment and (2) $\mathrm{Ca}^{2+}$ extrusion rate is linear to $\Delta\left[\mathrm{Ca}^{2+}\right]$ for mathematical simplicity. Under these assumptions, the time-derivative of the time-dependent change in $\Delta\left[\mathrm{Ca}^{2+}\right]_{\mathrm{i}}, y(t)$, is a balance between $\mathrm{Ca}^{2+}$ influx, $j(t)$, and $\mathrm{Ca}^{2+}$ clearance, so that

$$
\frac{d y(t)}{d t}=\frac{1}{1+\sum \kappa}(j(t)-\gamma \times y(t)),
$$

where $\Sigma \kappa$ represents the sum of the $\mathrm{Ca}^{2+}$ binding ratios of all $\mathrm{Ca}^{2+}$ buffers in the cell and $\gamma$ is a $\mathrm{Ca}^{2+}$ extrusion rate constant (Neher and Augustine, 1992; Lee et al., 2000; Kim et al., 2003). Rearrangement of equation 2 yields the following:

$$
j(t)=\frac{d y(t)}{d t}\left(1+\sum \kappa\right)+\gamma \times y(t) .
$$

The same relationship can be obtained by deconvolution of $y(t)$ with an impulse response of the linear system, which can be reasonably obtained from a single AP-induced $\mathrm{Ca}^{2+}$ transient (see Appendix). Note that $\gamma$ represents the sum of activities of all the $\mathrm{Ca}^{2+}$ clearance mechanisms including the $\mathrm{Ca}^{2+}$ transporters in the plasma membrane and in intracellular organelles, which drive $\Delta\left[\mathrm{Ca}^{2+}\right]_{\mathrm{i}}$ back to zero. The CaT evoked by a single AP at $t=0$, which induces an impulselike $\mathrm{Ca}^{2+}$ influx, is a special case where $j(t)=$ 0 during its decay phase. When $\mathrm{Ca}^{2+}$ extrusion and $\mathrm{Ca}^{2+}$ release from internal stores occur simultaneously, the $\mathrm{Ca}^{2+}$ release from internal stores can be calculated from $y(t)$ and $\gamma$ using equation 3 . Note that both $\mathrm{Ca}^{2+}$ influx through the plasma membrane and $\mathrm{Ca}^{2+}$ release from intracellular organelles can contribute to $j(t)$ with the same sign. Because we are interested in $j(t)$ during a posttetanic period, $\mathrm{Ca}^{2+}$ release rather than $\mathrm{Ca}^{2+}$ influx is assumed to constitute $j(t)$. Thus, we refer to $j(t)$ as " $\mathrm{Ca}^{2+}$ release" in the present study.

Data analysis. Data were analyzed using IgorPro (version 4.1; WaveMetrics, Lake Oswego, OR). Statistical data are expressed as mean \pm SEM, and $n$ indicates the number of cells studied. The significance of differences between two experimental conditions was evaluated using paired or nonpaired Student's $t$ test using a significance level of 0.05 .

\section{Results}

We investigated the CaTs evoked by HFS at the MFBs of hippocampal dentate GCs loaded via a patch pipette with an internal solution containing $50 \mu \mathrm{M}$ OGB1. $\sim 5$ min after the patch break-in, the mossy fiber, an axon of a dentate GC, became visible under the confocal microscope, and we could follow the mossy fiber up to $\sim 400 \mu \mathrm{m}$ (Fig. $1 A$ ). The MFBs with a cross-sectional area larger than $5 \mu \mathrm{m}^{2}$ were distinct from the smaller MFBs with regard to the time integral of $\mathrm{Ca}_{\text {res }}$ (Fig. 2D). Thus, we chose $5 \mu \mathrm{m}^{2}$ as the criterion for dividing MFBs into large MFBs and small en passant MFBs. The large MFBs, ranging in the cross-sectional area from $5.27 \mu \mathrm{m}^{2}$ to $18.46 \mu \mathrm{m}^{2}\left(8.50 \pm 0.34 \mu \mathrm{m}^{2}\right.$ in average, $n=$ $61)$, were irregularly shaped, and some of them had filopodial extensions and/or a region with a rarefaction of fluorescence within the bouton, probably indicative of an area in contact with postsynaptic thorny excrescence or large pool of synaptic vesicles (Hallermann et al., 2003) (Fig. $2 \mathrm{~A}$, inset). In contrast, the small MFBs were oval-shaped with cross-sectional area ranging from 1.24 to $4.67 \mu \mathrm{m}^{2}\left(2.63 \pm 0.15 \mu \mathrm{m}^{2} ; n=38\right)$ and had neither rarefaction of fluorescence nor filopodia (Fig. $2 B$, inset). 
Validity of the linear relationship between the total amount of posttetanic calcium release and $\int C a_{r e s} \mathrm{dt}$ At large MFBs, the fast decay phase of a tetanic stimulation (TS)-induced CaT (TS-CaT) was followed by a period of elevated $\left[\mathrm{Ca}^{2+}\right]_{\mathrm{i}}$ for tens of seconds after cessation of the HFS (Fig. $1 \mathrm{~B}$ ). At $2 \mathrm{~s}$ after cessation of HFS ( $33 \mathrm{~Hz}$ for $5 \mathrm{~s}$ ), the $\mathrm{Ca}^{2+}$ decay phase became distinctly slower (decay time constant, $30 \pm 2 \mathrm{~s}, n=13$; referred to as a slow decay phase) in comparison with the preceding fast-decay phase (Fig. $1 B$ ). Henceforth, we define the posttetanic $\Delta\left[\mathrm{Ca}^{2+}\right]_{\text {res }}$ as $\Delta\left[\mathrm{Ca}^{2+}\right]$ during the slow decay phase after $2 \mathrm{~s}$ after the end of HFS, which is set as $t=0$ in the following analysis.

The decay rate of a single AP-induced CaT (AP-CaT) during the slow decay phase (Fig. $1 C$, green and blue traces) was not different from that before HFS (Fig. $1 C$, red trace, summarized in $D$ ). From this observation, we inferred that the slowdecay phase was generated by continuing $\mathrm{Ca}^{2+}$ influx or release from internal stores after the HFS rather than by a decrease of $\mathrm{Ca}^{2+}$ clearance. We can calculate the time course of $\mathrm{Ca}^{2+}$ release from internal store [denoted by $j(t)$ ] during the slow-decay phase according to equation 3 , where the time course of $\Delta\left[\mathrm{Ca}^{2+}\right]_{\text {res }}$ is denoted by $y(t)$. When HFS at $33 \mathrm{~Hz}$ was applied for $5 \mathrm{~s}$, the $\Delta\left[\mathrm{Ca}^{2+}\right]_{\mathrm{i}}$ measured at $t=0[y(0)]$ was $235 \pm 24 \mathrm{nM}(n=13)$. The sum of $\mathrm{Ca}^{2+}$ binding ratios (denoted by $\Sigma_{\kappa}$ ) was assumed to be constant within the dynamic range of $y(t)$. This together with no significant change in the decay rate constant $\left(\tau^{-1}\right)$ of AP-CaTs imply that $\mathrm{Ca}^{2+}$ clearance $(\gamma)$ is largely constant during the slow decay phase (Eq. A3). When $\Sigma \kappa$ and $\gamma$ are constant, the time integral of $j(t)$ from $t=0$ to infinity yields [denoted by $J(\infty)$ ] (see Appendix):

$$
J(\infty) / \gamma=-y(0) \times \tau+\int_{0}^{\infty} y\left(t^{\prime}\right) d t^{\prime}
$$

indicating that $J(\infty) / \gamma$ is the difference between the time integral of $\Delta\left[\mathrm{Ca}^{2+}\right]_{\text {res }}$ (denoted by $\int \mathrm{Ca}_{\text {res }} d t$ ) and that of a single AP-CaT (or an impulse response; denoted by $A \tau$ ) with initial amplitude of $y(0)$. To evaluate the magnitudes of the two terms in equation 4 , we compared the $\int \mathrm{Ca}_{\text {res }} d t$ with the $A \tau$ at the same MFB. Figure $1 B$ demonstrates that the area under the AP-CaT is negligible compared with that under the TS-CaT [Incidentally, the amplitude of the AP-CaT in Figure $1 B$ was similar to $y(0)$.] The mean time constant of AP-CaTs $(\tau)$ in the presence of internal $50 \mu \mathrm{M}$ OGB1 was $290 \pm 14 \mathrm{~ms}(n=13)$. When HFS at $33 \mathrm{~Hz}$ was applied for $5 \mathrm{~s}$, the estimates for $\int \mathrm{Ca}_{\text {res }} d t$ were $6.4 \pm 0.7 \mu \mathrm{M} \cdot \mathrm{s}(n=13)$ and $2.3 \pm$ $0.2 \mu \mathrm{M} \cdot \mathrm{s}(n=16)$ at large and small MFBs, respectively. The $A \tau$ was calculated to be $0.066 \pm 0.007 \mu \mathrm{M} \cdot \mathrm{s}(n=13)$ at large MFBs and $0.034 \pm 0.003 \mu \mathrm{M} \cdot \mathrm{s}(n=16)$ at small MFBs, which are smaller than the second term by factors of $\sim 100$ and 70 at large and small MFBs, respectively. Therefore, we can approximate $J(t)$ as follows:
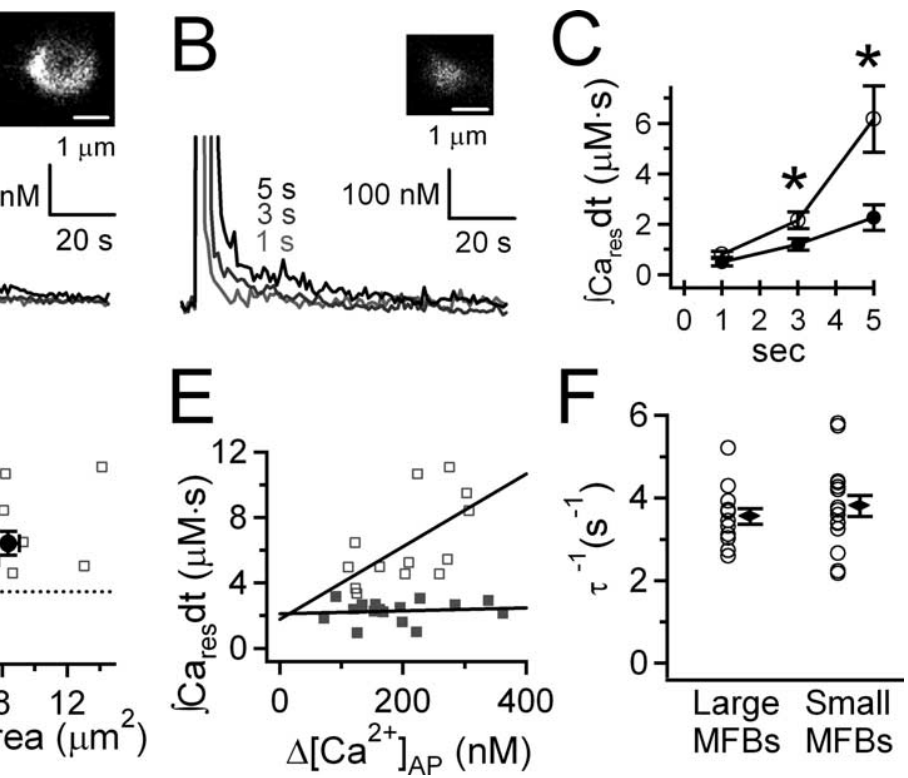

Figure 2. Differences in the amount of post-tetanic $\mathrm{Ca}_{\text {res }}$ between large MFBs and small en passant MFBs. $\boldsymbol{A}, \boldsymbol{B}$, Three superaveraged, and converted into $\left[\mathrm{C}^{2+}\right]$. Insets, Laser-scanned fluorescence images of the large MFB and the small en passant Open of AP-CaT. Different lines were fitted to the grouped data of large MFBs and to those of small en passant MFBs. $\boldsymbol{F}$, Values for $\tau^{-1}$ of AP-CaT at large and small MFBs (large MFBs, $3.6 \pm 0.2 s^{-1}, n=13$; small MFBs: $3.8 \pm 0.3 s^{-1}, n=16$ ).

$$
J(t) \cong \gamma \times \int_{0}^{t} y\left(t^{\prime}\right) d t^{\prime}
$$

The above equation indicates that the amount of total $\mathrm{Ca}^{2+}$ release during a post-tetanic slow-decay phase $\left[J(\infty)\right.$ or $\left.J_{\text {tot }}\right]$ is linear with regard to $\int \mathrm{Ca}_{\text {res }} d t$ with a proportionality factor, $\gamma$. Therefore, in the following analysis, we quantified the effect of a drug, $\mathrm{X}$, on $\mathrm{Ca}_{\text {res }}$ at an MFB as the ratio of $J_{\text {tot }}$ measured at the same bouton before and after the drug treatment, after confirming that $\mathrm{X}$ does not alter AP-CaTs (see Fig. 5Ac).

\section{Dependence of $\mathrm{Ca}_{\text {res }}$ on the strength of the HFS}

We tested whether the amount of $\mathrm{Ca}_{\text {res }}$ (quantified as $\int \mathrm{Ca}_{\text {res }} d t$ ) was dependent on the number of APs evoked during the HFS. When the stimulation frequency was fixed at $33 \mathrm{~Hz}$, a greater number of $\operatorname{APs}(33,99$, and $165 \mathrm{APs})$ resulted in a larger amount of $\mathrm{Ca}_{\text {res }}$ at the same MFB (Fig. $2 A, B$ ). The dependence of $\int \mathrm{Ca}_{\text {res }} d t$ on the duration of HFS at large MFBs was steeper compared with that at small MFBs (Fig. 2C). When the HFS duration was 3 or $5 \mathrm{~s}$, the amount of $\mathrm{Ca}_{\text {res }}$ at the large MFBs was significantly higher than that at the small MFBs $(n=5$ for each type of MFB; $p<$ 0.05).

To assess the dependence of $\int \mathrm{Ca}_{\text {res }} d t$ on the size of the MFB, the same HFS $(33 \mathrm{~Hz}, 5 \mathrm{~s})$ was applied to MFBs of various sizes, and the values for $\int \mathrm{Ca}_{\text {res }} d t$ were plotted as a function of the bouton area (Fig. 2D), showing that the value for $\int \mathrm{Ca}_{\text {res }} d t$ is clearly greater at large MFBs (bouton area, $>6.2 \mu \mathrm{m}^{2}$; open squares) than at small MFBs (bouton area, $<4.4 \mu \mathrm{m}^{2}$; filled squares). However, no clear correlation between $\int \mathrm{Ca}_{\text {res }} d t$ and bouton area was found within each group. To test whether the lower $\int \mathrm{Ca}_{\text {res }} d t$ 
at small MFB resulted from a lower $\mathrm{Ca}^{2+}$-increment induced by a single AP, the values for $\int \mathrm{Ca}_{\text {res }} d t$ were plotted as a function of the peak amplitude of AP-CaTs $\left(\Delta\left[\mathrm{Ca}^{2+}\right]_{\mathrm{AP}}\right)$ (Fig. $\left.2 \mathrm{E}\right)$. We found no difference in $\Delta\left[\mathrm{Ca}^{2+}\right]_{\mathrm{AP}}$ between two types of MFB $(207 \pm 20$ and $188 \pm 21 \mathrm{~nm}$ for large and small MFBs, respectively; $p=0.52$ ). Therefore, the lower $\int \mathrm{Ca}_{\text {res }} d t$ value at small MFBs may have resulted from the smaller amount of post-tetanic $\mathrm{Ca}^{2+}$ release into the cytosol $\left(J_{\text {tot }}\right)$, a high $\mathrm{Ca}^{2+}$ extrusion rate $(\gamma)$, or both (Eq. 5). To differentiate these possibilities, mean values for decay rate constant $\left(\tau^{-1}\right)$ of AP-CaTs at large and small MFBs were compared. Figure $2 F$ shows that $\tau^{-1}$ at large MFBs $\left(3.6 \pm 0.2 \mathrm{~s}^{-1} ; n=13\right)$ was not different from that of small MFBs $\left(3.8 \pm 0.3 \mathrm{~s}^{-1} ; n=16 ; p=0.47\right)$, indicating that $\mathrm{Ca}^{2+}$ extrusion rate $(\gamma)$ at the two types of MFBs may be similar under the assumption that $\Sigma k$ is not different at both type of boutons. This result suggests that the lower $\int \mathrm{Ca}_{\text {res }} d t$ at the small MFBs can be largely attributed to lower $J_{\text {tot }}$. It is noteworthy that no correlation was observed between $\int \mathrm{Ca}_{\text {res }} d t$ and $\Delta\left[\mathrm{Ca}^{2+}\right]_{\mathrm{AP}}$ at small MFBs, whereas $\int \mathrm{Ca}_{\text {res }} d t$ was largely proportional to $\Delta\left[\mathrm{Ca}^{2+}\right]_{\mathrm{AP}}$ at large MFBs (Fig. $2 E$ ).

\section{Differential contribution of mitochondria to $\mathrm{Ca}^{2+}$ buffering during HFS at large and small MFBs}

Mitochondria have been suggested as a $\mathrm{Ca}^{2+}$ sequestration mechanism at the axon terminals of many synapses (Tang and Zucker, 1997; David et al., 1998; David and Barrett, 2000; Billups and Forsythe, 2002; Suzuki et al., 2002; Kim et al., 2005; GarciaChacon et al., 2006). To test whether presynaptic mitochondria sequester cytosolic $\mathrm{Ca}^{2+}$ during HFS, we studied the effects of mitochondrial inhibitors on the build-up of $\left[\mathrm{Ca}^{2+}\right]_{\mathrm{i}}$ during HFS measured with a low-affinity $\mathrm{Ca}^{2+}$-indicator dye, OG5N (200 $\mu \mathrm{M})$. At the large MFB, HFS at $20 \sim 33 \mathrm{~Hz}$ for $5 \mathrm{~s}$ triggered an initial rapid increase in $\left[\mathrm{Ca}^{2+}\right]_{\mathrm{i}}$ followed by a slowly rising or plateau phase, reaching a peak $\left[\mathrm{Ca}^{2+}\right]_{\mathrm{i}}$ level of $\sim 1 \mu \mathrm{M}$ (Fig. $3 A a, A b$, black traces). Dissipation of the mitochondrial membrane potential $\left(\Delta \Psi_{\mathrm{m}}\right)$ using $1 \mu \mathrm{M}$ CCCP (Fig. $\left.3 A a\right)$ or $2 \mu \mathrm{M}$ antimycin A1 (Fig. 3Ab) together with $1 \mu \mathrm{M}$ oligomycin, augmented the peak $\Delta\left[\mathrm{Ca}^{2+}\right]_{\mathrm{i}}$ amplitude by approximately twofold (gray traces), indicating that mitochondrial $\mathrm{Ca}^{2+}$ uptake contributes to limiting the HFS-induced increase in presynaptic $\left[\mathrm{Ca}^{2+}\right]_{\mathrm{i}}$. In contrast, at small MFBs, the application of CCCP had little effects on the $\left[\mathrm{Ca}^{2+}\right]_{\mathrm{i}}$ build-up during HFS (Fig. $3 B$ ). We measured the peak $\Delta\left[\mathrm{Ca}^{2+}\right]_{\mathrm{i}}$ of TS-CaTs before and after the treatment of each drug at the same bouton, and quantified the effect of a drug as the ratio of the two peak $\Delta\left[\mathrm{Ca}^{2+}\right]_{\mathrm{i}}$ values (Fig. $3 C)$. These results suggest that mitochondria buffer the presynaptic $\mathrm{Ca}^{2+}$ build-up during HFS by taking up $\mathrm{Ca}^{2+}$ at large MFBs, but not at small MFBs.

\section{Dependence of $\mathrm{Ca}_{\text {res }}$ on mitochondrial $\mathrm{Ca}^{2+}$ uptake via the $\mathrm{Ca}^{2+}$ uniporter during HFS at large MFBs}

Mitochondrial $\mathrm{Ca}^{2+}$ uptake occurs via the mitochondrial $\mathrm{Ca}^{2+}$ uniporter located in the mitochondrial inner membrane (Bernardi, 1999). To elucidate whether mitochondrial $\mathrm{Ca}^{2+}$ uniporter is responsible for $\mathrm{Ca}^{2+}$-uptake during HFS, we studied the effects of Ru360 (60 $\mu \mathrm{M}$ in the patch pipette together with 200 $\mu \mathrm{M}$ OG5N), a specific blocker of mitochondrial $\mathrm{Ca}^{2+}$ uniporter, on the $\mathrm{Ca}^{2+}$-buildup during HFS at $33 \mathrm{~Hz}$ for 1,3 or $5 \mathrm{~s}$ (Fig. 4A). When the duration of HFS was $1 \mathrm{~s}$, Ru360 did not affect the mean peak $\left[\mathrm{Ca}^{2+}\right]_{\mathrm{i}}$ values of the CaTs both at large and small MFBs. At the HFS duration of 3 or 5 s, however, Ru360 significantly augmented the mean peak values of CaTs at the large MFBs, but not at the small MFBs. These results suggest that $\mathrm{Ca}^{2+}$ uniporter is

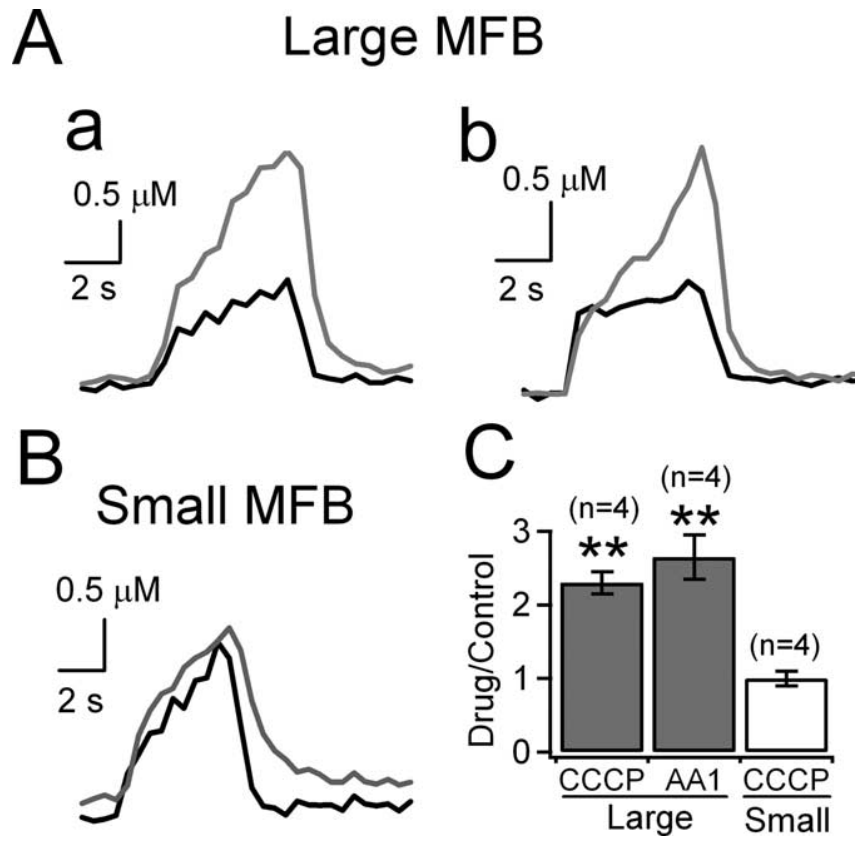

Figure 3. Mitochondrial buffering of the $\left[\mathrm{Ca}^{2+}\right]$ build-up during HFS. $0 G 5 \mathrm{~N}(200 \mu \mathrm{m})$ was included in the pipette solution to monitor CaTs during HFS $(20 \sim 33 \mathrm{~Hz}, 5 \mathrm{~s})$. Aa, The two superimposed CaTs were recorded at the same large MFB before (black line) and after application of $1 \mu \mathrm{m} \mathrm{CCCP}+1 \mu \mathrm{m}$ oligomycin (gray line). $\boldsymbol{A} \boldsymbol{b}$, Similar experiments were done using 2 $\mu \mathrm{m}$ antimycin $\mathrm{A} 1$ (AA1) $+1 \mu \mathrm{m}$ oligomycin at the large MFB. $B$, At small en passant MFBs, CaTs were evoked by HFS ( $33 \mathrm{~Hz}$ for $5 \mathrm{~s}$ ) under the control conditions (black line) and in the presence of $1 \mu \mathrm{m} \mathrm{CCCP}+1 \mu \mathrm{m}$ oligomycin (gray line). $C$, Mean values for the ratios of the peak $\Delta\left[\mathrm{Ca}^{2+}\right]$ of HFS-induced CaTs in the presence of mitochondrial uncoupler with respect to that in control conditions measured at the same MFBs. Gray and white bars represent large and small MFBs, respectively. ${ }^{* *} p<0.01$.

responsible for $\mathrm{Ca}^{2+}$ uptake into mitochondria during HFS at large MFBs, but not at small MFBs. Moreover, both dependence of $\int \mathrm{Ca}_{\text {res }} d t$ and that of Ru360-induced augmentation of the $\mathrm{Ca}^{2+}$-peak on the duration of HFS were steeper at large MFBs than at small MFBs, implying that mitochondrial $\mathrm{Ca}^{2+}$-uptake is closely associated with the generation of $\mathrm{Ca}_{\text {res }}$ (Figs. 2C, 4A).

Next, we tested whether $\mathrm{Ca}^{2+}$ uptake via the mitochondrial $\mathrm{Ca}^{2+}$ uniporter is required for the generation of $\mathrm{Ca}_{\text {res }}$. We recorded CaTs at the large MFBs using OGB1 in the presence of ruthenium red $(10 \mu \mathrm{M})$ or Ru360 $(30 \mu \mathrm{M})$ in the patch pipette (Fig. $4 B a, B b$ ). Both ruthenium red and Ru360 reduced the $\int \mathrm{Ca}_{\text {res }} d t$ to $\sim 30 \%$ of the control value $(1.93 \pm 0.57 \mu \mathrm{M} \cdot \mathrm{s}, n=6)$ (Fig. $4 B c$ ), which was comparable with the mean value for $\int \mathrm{Ca}_{\text {res }} d t$ at small MFBs $(2.27 \pm 0.65 \mu \mathrm{M} \cdot \mathrm{s} ; n=16 ; p=0.26)$. The plot of $\int \mathrm{Ca}_{\text {res }} d t$ values as a function of $\Delta\left[\mathrm{Ca}^{2+}\right]_{\mathrm{AP}}$ shows that the distribution of $\Delta\left[\mathrm{Ca}^{2+}\right]_{\mathrm{AP}}$ in the presence of the drugs was not different from that in control (Fig. $4 B d$ ). In contrast to the control condition, no correlation was observed between $\int \mathrm{Ca}_{\text {res }} d t$ and $\Delta[\mathrm{Ca}]_{\mathrm{AP}}$ when the mitochondrial $\mathrm{Ca}^{2+}$ uniporter was inhibited. These results suggest that $\mathrm{Ca}^{2+}$ uptake via the mitochondrial $\mathrm{Ca}^{2+}$ uniporter during HFS is a prerequisite for the generation of $\mathrm{Ca}_{\text {res }}$ at large MFBs.

\section{Mitochondrial NCE after HFS contributes to the $\mathrm{Ca}_{\text {res }}$ at large} MFBs, but not at small MFBs

Two pathways for mitochondrial $\mathrm{Ca}^{2+}$ efflux have been recognized based on cytosolic $\mathrm{Na}^{+}$dependence, with the primary efflux pathway of brain mitochondria being $\mathrm{Na}^{+}$-dependent (probably mitoNCX) (Crompton et al., 1978). We investigated whether NCE from presynaptic mitochondria is involved in the 

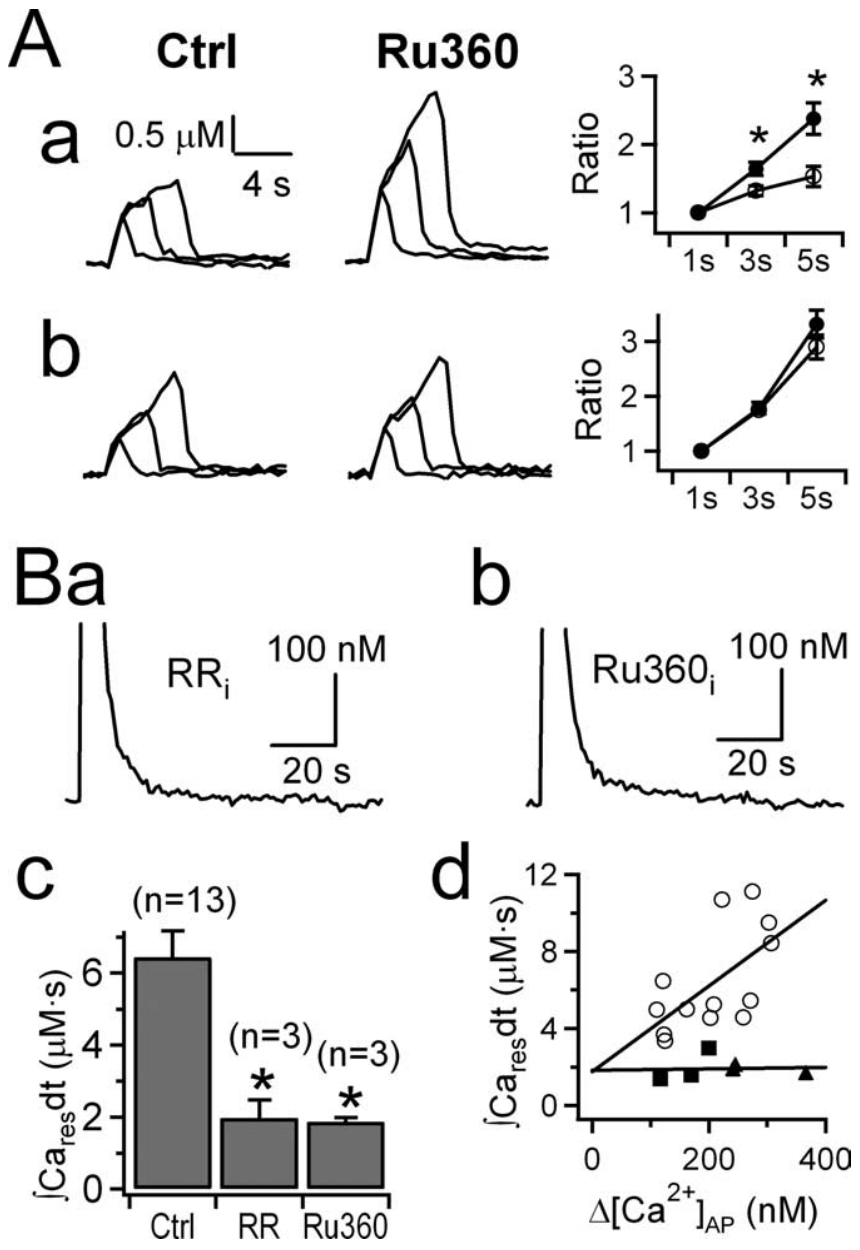

Figure 4. Role of mitochondrial $\mathrm{Ca}^{2+}$ uniporter in limiting $\mathrm{Ca}^{2+}$ buildup during $\mathrm{HFS}$ and in the generation of $\mathrm{Ca}_{\text {res }}$ at large MFBs. $\boldsymbol{A}$, CaTs at large MFBs $(\boldsymbol{A a} ; n=5$ for control and $n=7$ for Ru360) and those at small MFBs ( $\boldsymbol{A} \boldsymbol{b} ; n=7$ for control and $n=9$ for Ru360) induced by HFS (33 $\mathrm{Hz}$ ) for 1, 3, and $5 \mathrm{~s}$ were monitored without (left) or with (center) $60 \mu \mathrm{m}$ Ru360, a blocker of mitochondrial uniporter, in the pipette solution. Peak values of the CaTs were normalized relative to that for $1 \mathrm{~s}$ and then mean values for peak $\left[\mathrm{Ca}^{2+}\right]_{i}$ were plotted against the duration of HFS (right). $\boldsymbol{B} \boldsymbol{a}, \boldsymbol{B} \boldsymbol{b}$, Representative CaTs recorded at large MFBs evoked by HFS ( $33 \mathrm{~Hz}$ for $5 \mathrm{~s}$ ). CaTs were recorded with $10 \mu \mathrm{m}$ ruthenium red $(\boldsymbol{a})$ or $30 \mu \mathrm{m} \operatorname{Ru} 360(\boldsymbol{b})$ included in the pipette solution. $B c$, Mean values for $\int \mathrm{Ca}_{\text {res }} d t$ in control conditions $(6.4 \pm 0.7 \mu \mathrm{M} \cdot s ; n=13)$ and in the intracellular presence of ruthenium red ( $\mathrm{RR}_{\mathrm{i}}, 2.0 \pm 0.5 \mu \mathrm{m} \cdot \mathrm{s} ; n=3$ ) or Ru360 (Ru360, $1.9 \pm 0.1 \mu \mathrm{m} \cdot s ; n=3$ ). $\boldsymbol{B d}$, Dependence of $\int \mathrm{Ca}_{\text {res }} d t$ values under control conditions (open circles) and in the intracellular presence of ruthenium red (filled squares) or Ru360 (filled triangles) on the amplitude of AP-CaT $\left(\Delta\left[\mathrm{Ca}^{2+}\right]_{\mathrm{AP}}\right)$. Note no dependence of $\int \mathrm{Ca}_{\text {res }} d t$ on $\Delta\left[\mathrm{Ca}^{2+}\right]_{\mathrm{AP}}$ in the presence of ruthenium red or Ru360. ${ }^{*} p<0.02 .0 \mathrm{G5N}$ (200 $\left.\mu \mathrm{M}\right)$ or 0GB1 (50 $\left.\mu \mathrm{M}\right)$ was used as a $\mathrm{Ca}^{2+}$-indicator dye in $\boldsymbol{A}$ and $\boldsymbol{B}$, respectively.

generation of $\mathrm{Ca}_{\text {res }}$ at MFBs. Although $\mathrm{TPP}^{+}$dissipates $\Delta \Psi_{\mathrm{m}}$ at concentrations $>10 \mu \mathrm{M}$, it is a potent and selective inhibitor of mitochondrial NCE at low concentrations $\left(\mathrm{IC}_{50}, 0.2 \mu \mathrm{M}\right)$ with little adverse effect on mitochondrial respiration (Aiuchi et al., 1985; Karadjov et al., 1986; Wingrove and Gunter, 1986).

The bath application of $2 \mu \mathrm{M} \mathrm{TPP}{ }^{+}$attenuated the amount of $\mathrm{Ca}_{\text {res }}$ to $47 \%$ of the control value $(0.47 \pm 0.02 ; n=5)$ (Fig. $5 A a, A c)$. Another specific NCE inhibitor, CGP37157 (10 or 20 $\mu \mathrm{M})$, decreased the amount of $\mathrm{Ca}_{\text {res }}$ to a similar extent $(0.41 \pm$ $0.02 ; n=4)$ (Fig. $5 A b, A c$ ), indicating that the NCE from mitochondria is responsible for the generation of $\mathrm{Ca}_{\text {res }}$ at the large MFBs. To determine whether $\mathrm{TPP}^{+}$or CGP37157 affected the peak of TS-CaTs during HFS, the MFBs were loaded with OG5N together with OGB1 at the same molar concentration $(50 \mu \mathrm{M})$.

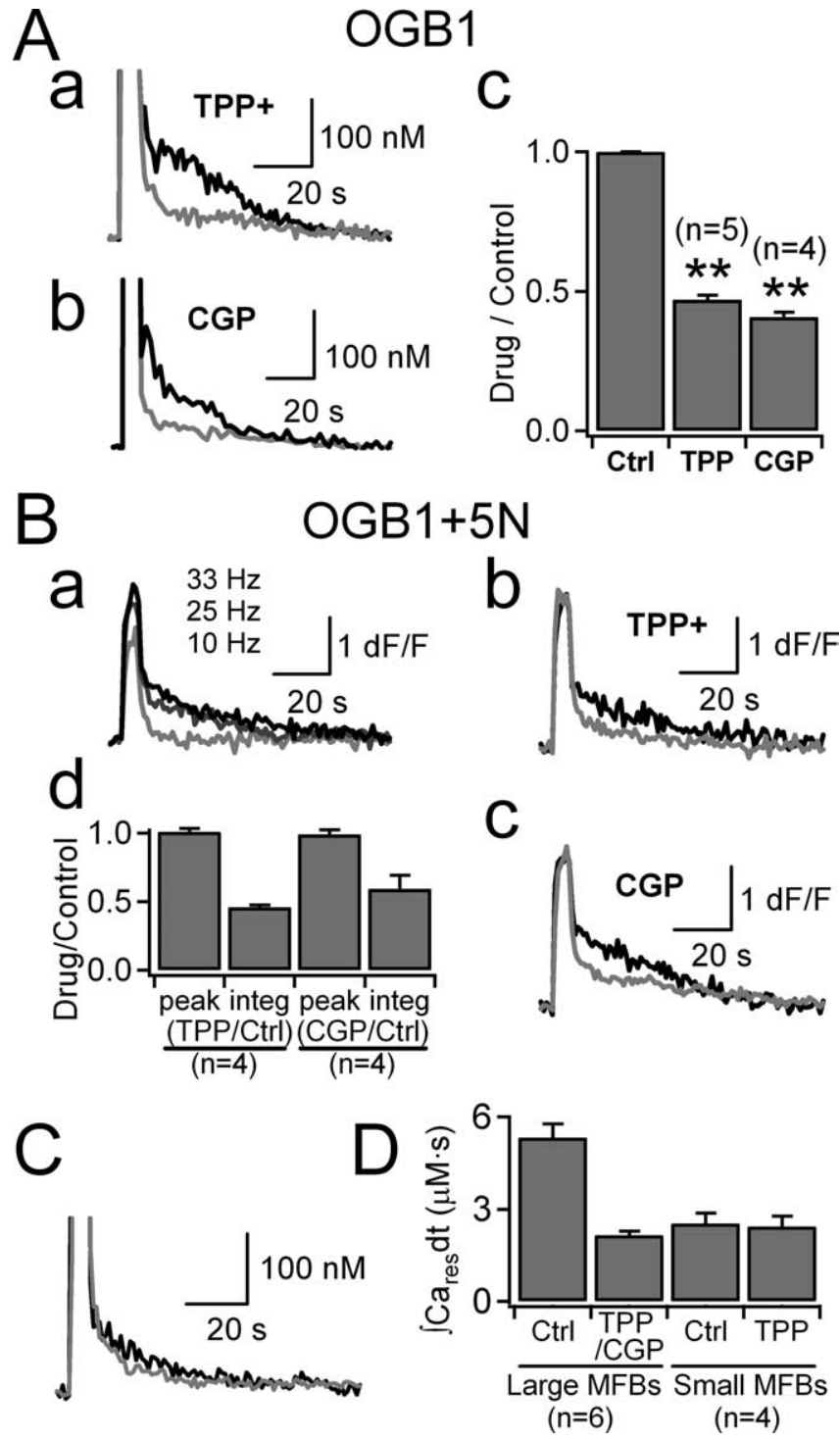

Figure 5. Effects of mitoNCX inhibitors on the post-tetanic $\mathrm{Ca}_{\text {res }}, \boldsymbol{A} \boldsymbol{a}, \boldsymbol{A} \boldsymbol{b}$, The two superimposed CaTs were evoked at a large MFB by HFS ( $33 \mathrm{~Hz}, 5 \mathrm{~s})$ under control conditions (black line) and in the presence of $2 \mu \mathrm{m} \operatorname{TPP}^{+}$( $\boldsymbol{a}$, gray line) or $10 \mu \mathrm{M}$ (GP37157 ( $\boldsymbol{b}$, gray line). $\boldsymbol{A c}, \int \mathrm{Ca}_{\text {res }} d t$ values were calculated from CaTs evoked by HFS ( $25 \mathrm{~Hz}$ or $33 \mathrm{~Hz}$ for $5 \mathrm{~s})$, and mean values for the ratio of $\int \mathrm{Ca}_{\text {res }} d t$ in the presence of mitoNCX blocker $\left(2 \mu \mathrm{M} \mathrm{TPP}{ }^{+}\right.$or $10 \sim 20 \mu \mathrm{M}$ (GP37157) to that in control conditions were plotted in the bar graph. ${ }^{* *} p<0.01 B$, Large MFBs were loaded with $50 \mu \mathrm{M} 0 \mathrm{G} 5 \mathrm{~N}$ together with $50 \mu \mathrm{M} 0 \mathrm{GB1}$. Ba, The three superimposed $\Delta F / F_{0}$ transients were evoked by $5 \mathrm{~s}$ HFS at different frequencies $(10 \mathrm{~Hz}, 25 \mathrm{~Hz}$ or $33 \mathrm{~Hz}) . \boldsymbol{B b}, \boldsymbol{B C}$, Two superimposed $\Delta F / F_{0}$ transients were evoked by $\mathrm{HFS}(33 \mathrm{~Hz}$ for $5 \mathrm{~s}$ ) before (black line) and after bath application of $2 \mu \mathrm{m} \mathrm{TPP}{ }^{+}$(gray line, $\boldsymbol{B} \boldsymbol{b}$ ) or $20 \mu \mathrm{m}$ CGP37157 (gray line, $\boldsymbol{B C}$ ). $\boldsymbol{B d}$, Relative values for peak $\Delta F / F_{0}$ (peak) and integrals of post-tetanic $\Delta F / F_{0}$ (integ) in the presence of TPP ${ }^{+}$or CGP37157 normalized to those under control conditions. $C$, Experiments similar to $A$ were done at small en passant MFBs. The two superimposed CaTs were evoked by HFS $(33 \mathrm{~Hz}, 5 \mathrm{~s})$ before (black line) and after application of $2 \mu \mathrm{m} \mathrm{TPP}{ }^{+}$(gray line). $\boldsymbol{D}$, Mean values for $\int \mathrm{Ca}_{\mathrm{res}} d t$ evoked by the same HFS ( $33 \mathrm{~Hz}$ for $5 \mathrm{~s}$ ) at large and small en passant MFBs before and after bath application of $2 \mu \mathrm{M} \mathrm{TPP}{ }^{+}$. Note that $\int \mathrm{Ca}_{\text {res }} d t$ at small MFBs is not different from that at large $\mathrm{MFBs}$ in the presence of mitoNCX blockers.

Under control conditions, not only the residual $\Delta F / F_{0}$, but also the peak $\Delta F / F_{0}$ values increased in proportional to the frequency of HFS, indicating that the peak $\Delta F / F_{0}$ values were not saturated during HFS (Fig. $5 \mathrm{Ba}$ ). Using the same techniques, we examined the effects of $\mathrm{TPP}^{+}$and CGP37157 on the peak and residual $\Delta F / F_{0}$ values. The HFS-induced $\Delta F / F_{0}$ transients before and after application of $2 \mu \mathrm{M} \mathrm{TPP}{ }^{+}$(Fig. 5Bb) or $20 \mu \mathrm{M} \mathrm{CGP37157} \mathrm{(Fig.}$ 
$5 B c$ ) were superimposed, showing that $\mathrm{TPP}^{+}$and CGP37157 attenuated the post-tetanic residual $\Delta F / F_{0}$ without altering the peak $\Delta F / F_{0}$ during HFS. These results, summarized in Figure $5 B d$, suggest that mitochondrial $\mathrm{Ca}^{2+}$ uptake during HFS and subsequent post-tetanic $\mathrm{Ca}^{2+}$ release by the mechanism of NCE generate the $\mathrm{Ca}_{\text {res }}$ at large MFBs.

The mean value for $\int \mathrm{Ca}_{\text {res }} d t$ measured at large MFBs in the presence of $\mathrm{TPP}^{+}$or CGP37157 $(2.14 \pm 0.12 \mu \mathrm{M} \cdot \mathrm{s} ; n=6)$ was comparable with that induced by the same HFS $(33 \mathrm{~Hz}, 5 \mathrm{~s})$ at small MFBs under control conditions $(2.28 \pm 0.16 \mu \mathrm{M} \cdot \mathrm{s} ; n=16)$ (Fig. $5 D$ ). Furthermore, the bath application of $2 \mu \mathrm{M} \mathrm{TPP}{ }^{+}$had no significant effect on the amount of $\mathrm{Ca}_{\text {res }}$ at the small MFBs $(2.53 \pm 0.33$ vs $2.43 \pm 0.33 \mu \mathrm{M} \cdot s ; p=0.818 ; n=4)($ Fig. $5 C, D)$. These results suggest two different mechanisms, mitochondriadependent and nonmitochondrial, for the generation of $\mathrm{Ca}_{\text {res }}$ at MFBs, with the mitochondria-dependent mechanism occurring exclusively at large MFBs.

\section{Effect of $\mathrm{Ca}^{2+}$ buffers on the time course of $\Delta\left[\mathrm{Ca}^{2+}\right]_{\text {res }}$ at large MFBs}

Whole-cell recording of a GC alters the $\mathrm{Ca}^{2+}$ dynamics of MFBs because of gradual washout of endogenous $\mathrm{Ca}^{2+}$ buffers including calbindin- $\mathrm{D}_{28 \mathrm{~K}}$ and the introduction of $\mathrm{C} \mathrm{Ca}^{2+}$-indicator dye (Müller et al., 2005). It is important whether altered presynaptic $\mathrm{Ca}^{2+}$ buffering substantially influences the time course of $\Delta\left[\mathrm{Ca}^{2+}\right]_{\text {res }}$. We can predict the possible effects of $\mathrm{Ca}^{2+}$ buffer on the time course of $\Delta\left[\mathrm{Ca}^{2+}\right]_{\text {res }}$ based on the differentiation of equation 5 , which yields the following:

$$
y(t) \cong j(t) / \gamma
$$

This equation implies that $y(t)$ closely reflects that of $j(t)$, and does not depend on the properties of intracellular $\mathrm{Ca}^{2+}$ buffer. Exogenous $\mathrm{Ca}^{2+}$ buffers may alter $\Delta\left[\mathrm{Ca}^{2+}\right]_{\mathrm{i}}$ during HFS, and thus mitochondrial $\mathrm{Ca}^{2+}$ uptake during HFS, which in turn can affect $j(t)$. The linear superposition model for a TS-CaT, however, predicts that $\mathrm{Ca}^{2+}$ buffers alter only the time course to reach steady-state $\left[\mathrm{Ca}^{2+}\right]_{\mathrm{i}}$ during HFS with no effect on the steadystate $\left[\mathrm{Ca}^{2+}\right]_{\mathrm{i}}$ (Regehr et al., 1994). The linear superposition model together with equation 6 predict that intracellular $\mathrm{Ca}^{2+}$ buffers have a limited effect on $y(t)$ at large MFBs. To test this hypothesis, we measured the decay time courses of AP-CaTs and TS-CaTs at various concentrations of a $\mathrm{Ca}^{2+}$-indicator dye, which acts as a $\mathrm{Ca}^{2+}$ buffer, at the same large MFB, while it was being loaded with $200 \mu \mathrm{M}$ OGB1 through a pipette to the soma (supplemental Fig. $1 A$, available at www.jneurosci.org as supplemental material). The increase in [OGB1] accompanied the decrease in the peak amplitude of AP-CaT and the increase in its decay time constant, indicative of increase in the $\mathrm{Ca}^{2+}$ buffer concentration at the MFB (Neher and Augustine, 1992; Kim et al., 2003) (supplemental Fig. $1 B$, available at www.jneurosci.org as supplemental material). In contrast to the altered kinetics of AP-CaTs, the time course of $\Delta\left[\mathrm{Ca}^{2+}\right]_{\text {res }}$ evoked by HFS $(33 \mathrm{~Hz}$, $5 \mathrm{~s}$ ) were not altered (supplemental Fig. $1 C, D$, available at www.jneurosci.org as supplemental material). This result supports the prediction about the time course of $\Delta\left[\mathrm{Ca}^{2+}\right]_{\text {res }}$ based on equation 6 . In addition, it is expected that the time course of $\Delta\left[\mathrm{Ca}^{2+}\right]_{\text {res }}$ in vivo, in the absence of an exogenous $\mathrm{Ca}^{2+}$ indicator dye, would be similar to that observed in the present study.
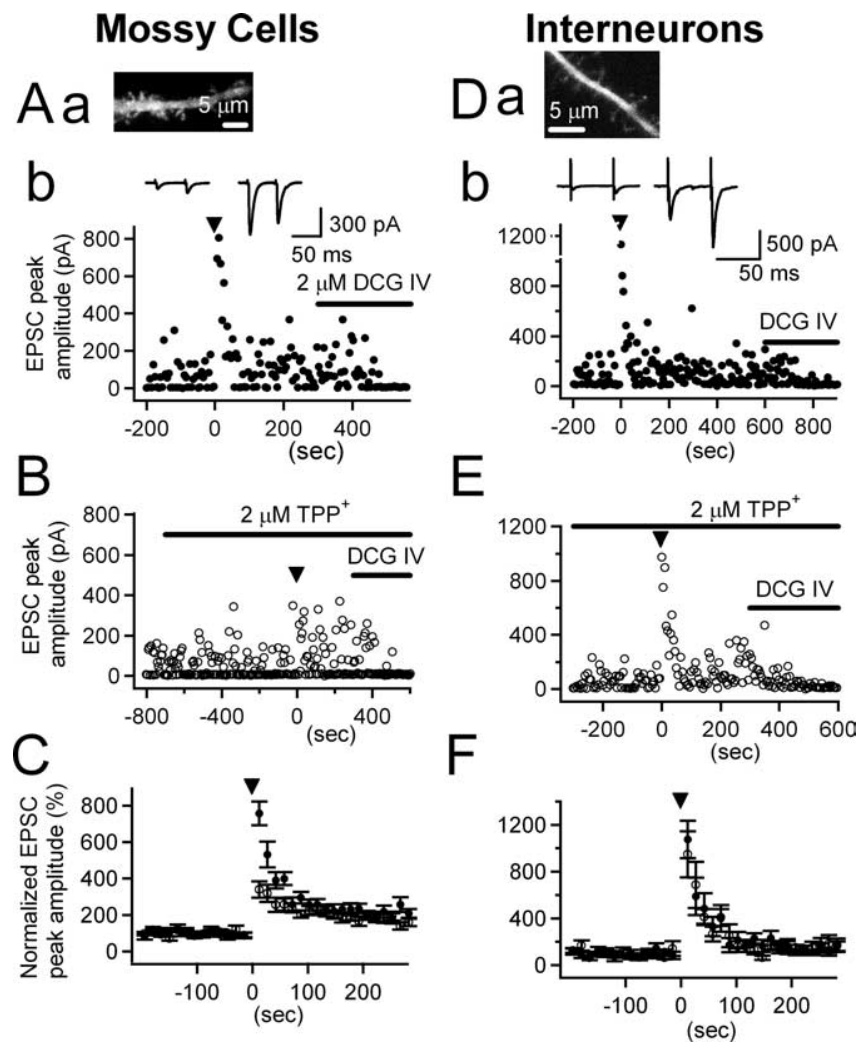

Figure 6. $\boldsymbol{A}-\boldsymbol{F}$, Effects of mitoNCX inhibitors on PTP at the MF synapse onto the hilar mossy cell (MF $\rightarrow M C$ synapse, $\boldsymbol{A}-\boldsymbol{C}$ ) and at that onto the hilar interneuron (MF $\rightarrow$ Hl synapse, $\boldsymbol{D}-\boldsymbol{F}$ ). $A \boldsymbol{a}, \mathbf{D a}$, Fluorescence micrograph of a dendrite of the $\mathrm{MC}$ and the HI located in the deep hilar region. Note the thorny excrescences in $\boldsymbol{A a}$ and thin spines on the dendritic shaft in $\mathbf{D a} . \mathbf{A b}, \boldsymbol{D b}$ EPSCs were recorded from the MC $(\boldsymbol{A} \boldsymbol{b})$ or the $\mathrm{HI}(\boldsymbol{D} \boldsymbol{b})$ by applying paired pulses (50 ms interval) stimulation (2-25 V) at a rate of $0.2 \mathrm{~Hz}$. After baseline transmissions (BTs) were recorded for 5-10 min, HFS at $25 \mathrm{~Hz}$ was applied for $5 \mathrm{~s}$ (inverted triangle) and the time-dependent changes in the EPSC amplitude were recorded. DCG-IV $(2 \mu \mathrm{m})$ was applied at the end of experiments to confirm MF stimulation. Insets of $\boldsymbol{A} \boldsymbol{b}$ and $\boldsymbol{D} \boldsymbol{b}$ show averaged traces of 36 EPSCs during BT (left) and of six EPSCs during the PTP phase (right). $\boldsymbol{B}, \boldsymbol{E}$, Experiments similar to $\boldsymbol{A} \boldsymbol{b}$ and $\boldsymbol{D} \boldsymbol{b}$ were conducted in the presence of $2 \mu \mathrm{M}$ TPP ${ }^{+}$, which was applied for at least 10 min before applying a HFS ( $25 \mathrm{~Hz}, 5 \mathrm{~s}$ ) while monitoring BT. $\boldsymbol{C}, \boldsymbol{F}$, Three consecutive EPSCs from each cell were averaged, and then the resulting means were averaged again over the cells recorded. The time course of PTP under control conditions (filled circles; $n=15$ for MC and $n=7$ for HI) and in the presence of $2 \mu \mathrm{M} \mathrm{TPP}{ }^{+}$(open circles; $n=12$ for MC and $n=5$ for HI) are shown.

The mitochondrial NCE contributes to PTP specifically at MF synapses onto mossy cell

We showed that NCE from mitochondria is involved in the generation of $\mathrm{Ca}_{\text {res }}$ specifically at large MFBs but not at small MFBs. Large MFBs terminate exclusively on the thorny excrescences of hilar MCs and CA3 pyramidal cells (PCs), while small en passant MFBs target GABAergic interneurons (Claiborne et al., 1986; Acsady et al., 1998). We hypothesized that mitochondriadependent presynaptic $\mathrm{Ca}_{\text {res }}$ may influence PTP at $\mathrm{MF} \rightarrow \mathrm{MC}$ synapses, but not at MF synapses onto HIs. To test this hypothesis, we examined EPSCs evoked by extracellular stimulation of MFs in the MC. MCs were identified by the presence of thorny excrescences on dendrites (see Materials and Methods) (Lübke et al., 1998) (Fig. 6Aa).

After assessing the baseline amplitudes of EPSCs evoked by extracellular paired stimuli (interstimulus interval, $50 \mathrm{~ms}$ ) at 0.2 $\mathrm{Hz}$ for $5-10 \mathrm{~min}$, we applied HFS at $25 \mathrm{~Hz}$ for $5 \mathrm{~s}$, and then resumed the paired stimuli at $0.2 \mathrm{~Hz}$ to monitor the change in synaptic strength. A time course of the change in EPSC amplitudes was depicted from ensemble averages over mean ampli- 
tudes of three consecutive EPSCs of each cell (Fig. 6C,F). PTP was measured as the average of the first three EPSC amplitudes $(7,12$, and $17 \mathrm{~s}$ after the end of HFS) compared with the control EPSC amplitude.

The HFS invariably induced immediate and short-lasting PTP of EPSCs, which was usually followed by a longer-lasting synaptic potentiation (probably MF long-term potentiation). The average PTP of EPSCs was $756 \pm 64 \%(n=15)$ (Fig. $6 A, C$, filled circles). The mean paired pulse ratio (PPR) significantly decreased from $2.22 \pm 0.12$ in basal transmission to $1.09 \pm 0.08$ during PTP $(n=$ $15 ; p<0.01)$. Furthermore, PTP was accompanied by a significant decrease in the failure rate, from $0.23 \pm 0.04$ to $0.01 \pm 0.01$ (measured during $30 \mathrm{~s}$ immediately after HFS; $n=15 ; p<0.01$ ), indicative of a presynaptic locus of PTP at the MF $\rightarrow$ MC synapse.

Previous simultaneous recordings of presynaptic $\left[\mathrm{Ca}^{2+}\right]$ and excitatory field potential at mossy fiber synapse in CA3 revealed that the magnitude of PTP is well correlated with that of $\Delta\left[\mathrm{Ca}^{2+}\right]_{\text {res }}$, but PTP outlasts $\mathrm{Ca}_{\text {res }}$ (Regehr et al., 1994). Consistently, we found that the decay time constant of ensembleaveraged PTP at MF $\rightarrow \mathrm{MC}$ synapse $(31.8 \mathrm{~s})$ was slower than that of $\Delta\left[\mathrm{Ca}^{2+}\right]_{\text {res }}(17.7 \pm 2.5 \mathrm{~s} ; n=5)$ at large MFBs, when the time course was analyzed $7 \mathrm{~s}$ after the end of HFS ( $25 \mathrm{~Hz}, 5 \mathrm{~s})$.

To investigate the dependence of PTP on presynaptic mitochondrial NCE, similar experiments were performed in the presence of $2 \mu \mathrm{M} \mathrm{TPP}{ }^{+}$. The baseline EPSC size was not significantly affected by the $\mathrm{TPP}^{+}$treatment for $>10 \mathrm{~min}(59.8 \pm 8.7 \mathrm{vs}$ $57.3 \pm 5.7 \mathrm{pA} ; n=5 ; p=0.817)$. However, PTP induced by the same HFS $(25 \mathrm{~Hz}, 5 \mathrm{~s})$ was significantly reduced in the presence of $\mathrm{TPP}^{+}(338 \pm 45 \% ; n=12 ; p<0.01)$ (Fig. 6B, $C$, open circles). The summary plot of normalized peak amplitudes of EPSCs depicted in Figure $6 C$ shows that $2 \mu \mathrm{M} \mathrm{TPP}{ }^{+}$lowered the PTP by $55.2 \%$. We also examined the effects of another mitochondrial NCE inhibitor, CGP37157 on the PTP of EPSCs at the MF $\rightarrow$ MC synapse. Consistent with the effects of $\mathrm{TPP}^{+}, 20 \mu \mathrm{M} \mathrm{CGP37157}$ significantly reduced the PTP evoked by the same HFS (512 \pm $84 \% ; n=12 ; p<0.05$ ) (supplemental Fig. 2, gray circles, available at www.jneurosci.org as supplemental material).

To test the dependence of PTP on the mitochondrial NCE at the synapses of small MFBs, we performed a similar set of experiments in hilar interneurons, onto which small MFBs terminate (Acsady et al., 1998). Because we have done majority of $\mathrm{Ca}^{2+}$ imaging experiments at MFBs located $>100 \mu \mathrm{m}$ apart from the subgranular border, we avoided interneurons in the subgranular layer, and examined EPSCs at MF synapses on the interneurons located in the deep hilar region. We considered deep hilar neurons devoid of thorny excrescence, which were usually found to have the dendrites covered with long and thin spines (Fig. 6Da), as HIs. The same HFS $(25 \mathrm{~Hz}, 5 \mathrm{~s})$ induced the PTP at the $\mathrm{MF} \rightarrow \mathrm{HI}$ synapses (Fig. $6 \mathrm{Db}$ ), which was accompanied by decreases in PPR (from $2.30 \pm 0.21$ to $1.46 \pm 0.16, n=7, p<0.01$ ) and in the failure rate (from $0.37 \pm 0.01$ to $0.08 \pm 0.01 ; n=7 ; p<$ 0.01 ), indicative of the presynaptic locus of PTP. The decay time constant of PTP at the MF $\rightarrow$ HI synapse $(29.2 \mathrm{~s}$ ) was slower than that of residual $\left[\mathrm{Ca}^{2+}\right](15.0 \pm 1.9 \mathrm{~s}, n=11)$ at small MFBs. In spite that the amount of $\mathrm{Ca}_{\text {res }}$ was lower at small MFBs (Fig. 2), the magnitude of PTP at the $\mathrm{MF} \rightarrow \mathrm{HI}$ synapses was larger $(1075 \pm 161 \% ; n=7)$ (Fig. 6Db,F, filled circles) than at the $\mathrm{MF} \rightarrow \mathrm{MC}$ synapses $(p<0.05)$. Furthermore, PTP at the $\mathrm{MF} \rightarrow \mathrm{HI}$ synapse was not altered by $2 \mu \mathrm{M} \mathrm{TPP}{ }^{+}(948 \pm 197 \%)$ (Fig. 6E, F, open circles), implying that mitochondria-dependent $\mathrm{Ca}_{\text {res }}$ does not contribute to the PTP at the $\mathrm{MF} \rightarrow \mathrm{HI}$ synapse.

These results suggest that the presynaptic mechanism of PTP at $\mathrm{MF} \rightarrow \mathrm{MC}$ synapses is distinct from that at $\mathrm{MF} \rightarrow \mathrm{HI}$ synapses
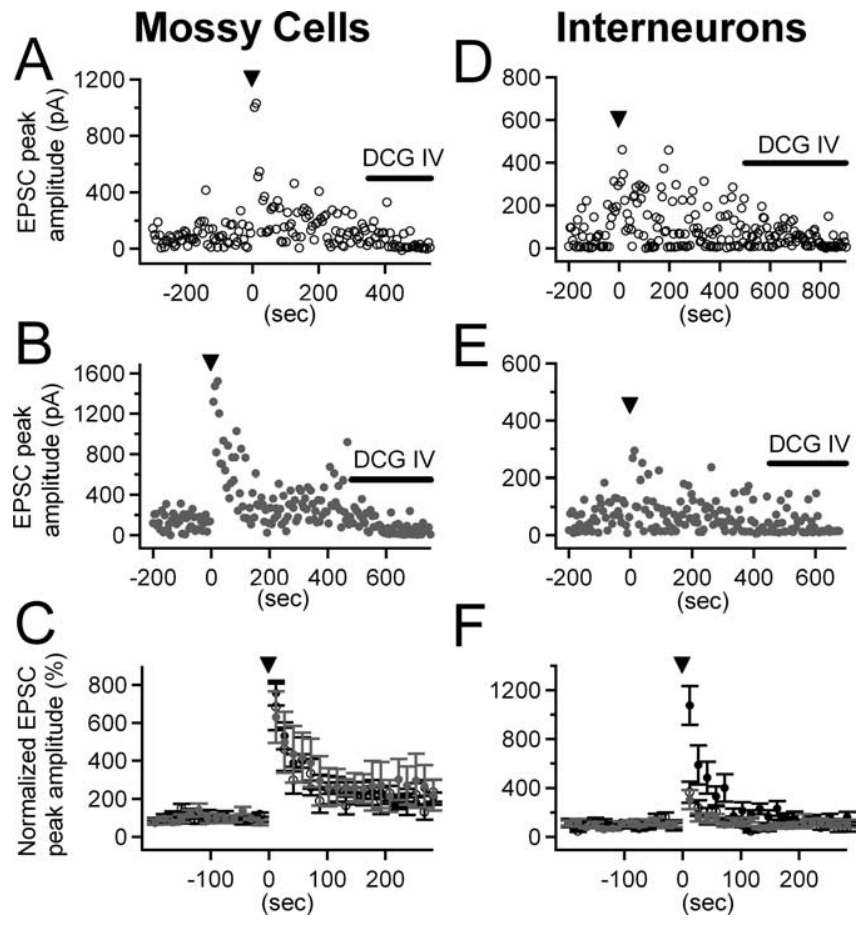

Figure 7. Differential involvement of PKC in PTP at the MF $\rightarrow$ MC and at the MF $\rightarrow H$ II synapses. $\boldsymbol{A}, \boldsymbol{B}, \boldsymbol{D}, \boldsymbol{E}$, Experiments similar to Figure 6 were done in the presence of $5 \mu \mathrm{m}$ chelerythrine $(\boldsymbol{A}$ and $\boldsymbol{D})$ or $1 \mu \mathrm{m}$ Ro-31-8220 ( $\boldsymbol{B}$ and $\boldsymbol{E}$ ). $\boldsymbol{C}$ and $\boldsymbol{F}$, Time courses of ensemble-averaged EPSC amplitudes (obtained in the same way as in Fig. 6C,F) under control conditions (filled circles; same traces from Fig. $6 C, F)$ and in the presence of chelerythrine (open circles, $n=5$ for $M C$ and $n=7$ for HI) or Ro-31-8220 (gray circles; $n=6$ for MC and $n=7$ for $\mathrm{HI}$ ) are shown.

and that mitochondria-dependent $\mathrm{Ca}_{\text {res }}$ is responsible for the $\mathrm{PTP}$ selectively at $\mathrm{MF} \rightarrow \mathrm{MC}$ synapses.

\section{Protein kinase C contributes to PTP specifically at MF synapses onto hilar interneuron}

Previously, activation of PKC has been proposed as underlying mechanisms for PTP at the synapses in hippocampus and in cerebellum (Alle et al., 2001; Brager et al., 2003; Beierlein et al., 2007; Wierda et al., 2007). We studied whether PKC is differentially involved in $\mathrm{PTP}$ at $\mathrm{MF} \rightarrow \mathrm{MC}$ and $\mathrm{MF} \rightarrow \mathrm{HI}$ synapses.

To investigate the dependence of PTP on PKC activation, slices were perfused with aCSF containing a PKC inhibitor at least $1 \mathrm{~h}$ ahead of each recording in the recording chamber. The pretreatment with $5 \mu \mathrm{M}$ chelerythrine exclusively attenuated PTP at the $\mathrm{MF} \rightarrow \mathrm{HI}$ synapse (Fig. $7 D$ ), but not at the $\mathrm{MF} \rightarrow \mathrm{MC}$ synapse (Fig. 7A). Summary plots indicate that chelerythrine diminished $\mathrm{PTP}$ at the $\mathrm{MF} \rightarrow \mathrm{HI}$ synapse $(365 \pm 87 \% ; n=7 ; p<0.01)$ (Fig. $7 F$, open circles), although it had no effect on PTP at the $\mathrm{MF} \rightarrow \mathrm{MC}$ synapse $(683 \pm 123 \% ; n=5)$ (Fig. $7 C$, open circles).

To further narrow down the identity of PKC involved in the mossy fiber PTP, we tested the effects of another PKC inhibitor Ro-31-8220, which selectively inhibits $\mathrm{Ca}^{2+}$-dependent PKC isoforms plus PKCe. After at least $1 \mathrm{~h}$ perfusion of the slice with aCSF containing $1 \mu \mathrm{M}$ Ro-31-8220, similar experiments were performed both at $\mathrm{MF} \rightarrow \mathrm{MC}$ synapse (Fig. $7 B$ ) and at $\mathrm{MF} \rightarrow \mathrm{HI}$ synapse (Fig. 7E). Ro-31-8220 exclusively diminished PTP at the $\mathrm{MF} \rightarrow \mathrm{HI}$ synapse $(306 \pm 79 \% ; n=7 ; p<0.01)$ (Fig. $7 F$, gray circles), but not at the MF $\rightarrow$ MC synapse $(630 \pm 136 \% ; n=6)$ (Fig. 7C, gray circles). These results suggest that activation of $\mathrm{PKC}$ is involved in PTP at the MF $\rightarrow \mathrm{HI}$ synapse, but not at the 
$\mathrm{MF} \rightarrow \mathrm{MC}$ synapse, and that $\mathrm{PKC}$ and mitochondria are involved at complementary MF synapses in the hippocampal hilar region.

\section{Discussion}

The present study demonstrated that mitochondria- and PKCdependent PTP occurs at MF synapses onto the hilar mossy cells and interneurons, respectively. The differential PTP mechanisms depending on target cells can be ascribed to the differences between large and small MFBs with regard to the activitydependent regulation of $\mathrm{Ca}^{2+}$ dynamics and signaling pathways involving PKC. Mossy fibers innervate hilar interneurons not only via small MFBs but also via bulbous endings of hair-like filopodial extension from large MFBs (Acsady et al., 1998). Because of technical difficulty, we could not address the question whether mitochondrial $\mathrm{Ca}_{\text {res }}$ occurs at bulbous endings. Our finding that $\mathrm{TPP}^{+}$had no effect on the $\mathrm{PTP}$ at $\mathrm{MF} \rightarrow \mathrm{HI}$ synapses suggests that mitochondria little contribute to $\mathrm{Ca}_{\text {res }}$ at bulbous endings.

Exclusive mitochondrial involvement in PTP at the synapse of large MFBs is consistent with our observation of different $\mathrm{Ca}^{2+}$. dynamics at two types of MFBs. It is obscure, however, what is responsible for differential activation of PKC at two types of MFB. Figure $4 A$ showed that lack of mitochondrial uptake at small MFBs resulted in the higher $\mathrm{Ca}^{2+}$ build-up during HFS compared with the large MFBs. The differential $\mathrm{Ca}^{2+}$ build-up in response to the same HFS in turn may cause differential activation of PKC at the two types of MFBs. Alternatively, PKC or its targets may be differentially distributed at two types of MFBs.

\section{Pathways for post-tetanic $\mathrm{Ca}^{2+}$ release from mitochondria} The present study suggests that mitochondrial $\mathrm{Ca}^{2+}$-uniporter and mitoNCX are major pathways for $\mathrm{Ca}^{2+}$ uptake during HFS and post-tetanic $\mathrm{Ca}^{2+}$ release, respectively. The buildup of $\left[\mathrm{Ca}^{2+}\right]_{\mathrm{i}}$ activates the $\mathrm{Ca}^{2+}$-uniporter, through which calcium ions pass down the electrochemical gradient across the mitochondrial inner membrane (Kirichok et al., 2004). Invasion of high-frequency APs to the axon terminal accompanies an increases in $\left[\mathrm{Na}^{+}\right]_{\mathrm{i}}$ (Zhong et al., 2001). Given that the decay of $\left[\mathrm{Na}^{+}\right]_{\mathrm{i}}$ is rather slower than that of $\left[\mathrm{Ca}^{2+}\right]_{\mathrm{i}}$ after cessation of HFS (Regehr, 1997), the ionic conditions after a rapid $\mathrm{Ca}^{2+}$ decay phase (high $\left[\mathrm{Na}^{+}\right]_{\mathrm{i}}$ and relatively low $\left[\mathrm{Ca}^{2+}\right]_{\mathrm{i}}$ ) may provide an electrochemical gradient favorable for sequestrated $\mathrm{Ca}^{2+}$ to be released into cytosol via mitoNCX.

It should be noted that $\mathrm{TPP}^{+}$has reduced PTP both at the $\mathrm{NMJ}$ of crayfish and at $\mathrm{MF} \rightarrow \mathrm{MC}$ synapses, but at different concentrations (Tang and Zucker, 1997). TPP ${ }^{+}$dissipates the $\Delta \psi_{\mathrm{m}}$ in a dose-dependent manner. Such adverse effects become overt at concentrations $>10 \mu \mathrm{M}$. At lower concentrations, however, $\mathrm{TPP}^{+}$had little effect on mitochondrial respiration, and it had no adverse effect when pyruvate is provided as a substrate (Aiuchi et al., 1985). The $\mathrm{Ca}_{\text {res }}$ at the NMJ was blocked by $10 \mu \mathrm{M} \mathrm{TPP}{ }^{+}$, and this was accompanied by a significant increase in the peak of TS-CaT, indicative of compromised mitochondrial $\mathrm{Ca}^{2+}$ uptake (Tang and Zucker, 1997). Moreover, mitochondrial $\mathrm{Ca}^{2+}$ release was not blocked by CGP37157, a specific blocker of mitoNCX, implying that the $\mathrm{Na}^{+}$-independent efflux of $\mathrm{Ca}^{2+}$ is a major route for mitochondrial $\mathrm{Ca}^{2+}$ release (Zhong et al., 2001). In the present study, $2 \mu \mathrm{M} \mathrm{TPP}{ }^{+}$or $10 \mu \mathrm{M}$ CGP37157 significantly reduced $\int \mathrm{Ca}_{\text {res }} d t$, but neither had an effect on the $\left[\mathrm{Ca}^{2+}\right]_{\mathrm{i}}$ build-up during HFS, indicating that mitochondrial $\mathrm{Ca}^{2+}$ uptake was not inhibited by these drugs (Fig. 5). These results support the idea that $\mathrm{TPP}^{+}$at low concentrations is relatively specific for mi-
toNCX with little effect on mitochondrial respiration (Aiuchi et al., 1985; Wingrove and Gunter, 1986).

\section{Mitochondrial and nonmitochondrial mechanisms of $\mathrm{Ca}_{\text {res }}$} At large MFBs, inhibitors of mitochondrial NCE did not completely abolish the $\mathrm{Ca}_{\text {res }}$. One explanation is the possible involvement of $\mathrm{Na}^{+}$-independent mitochondrial $\mathrm{Ca}^{2+}$ release pathway such as $\mathrm{Ca}^{2+} / \mathrm{H}^{+}$exchanger, reversal of $\mathrm{Ca}^{2+}$ uniporter or mitochondrial permeability transition pore (Bernardi, 1999). However, these possibilities are not likely because the amount of $\mathrm{Ca}_{\text {res }}$ insensitive to blockers of $\mathrm{Ca}^{2+}$ uniporter was comparable with that insensitive to mitoNCX blockers (compare Figs. $4 B c, 5 D$ ). This result indicates that the $\mathrm{Ca}_{\text {res }}$ at a large MFB is generated by mitochondrial and nonmitochondrial mechanisms. To investigate whether $\mathrm{Ca}^{2+}$ release from endoplasmic reticulum (ER) or an extracellular $\mathrm{Ca}^{2+}$ influx via presynaptic kainate channels play a role in the generation of the nonmitochondrial $\mathrm{Ca}_{\text {res }}$, we tested the effect of CNQX and thapsigargin on the $\mathrm{Ca}_{\text {res }}$ and the peak amplitude of TS-CaTs, respectively. Neither of them had significant effects (data not shown), implying that ER and kainate receptor may not be responsible for the nonmitochondrial $\mathrm{Ca}_{\text {res }}$.

The nonmitochondrial $\mathrm{Ca}_{\text {res }}$ at large MFBs shares several characteristics with the $\mathrm{Ca}_{\text {res }}$ at small MFBs with regard to the amount of $\mathrm{Ca}_{\text {res }}$ (compare Figs. 2 with $4 C, 5 D$ ) and its independence of the $\Delta\left[\mathrm{Ca}^{2+}\right]_{\mathrm{AP}}$ (Figs. $2 E, 4 B d$ ), indicating that nonmitochondrial $\mathrm{Ca}_{\text {res }}$ exists at both types of boutons, whereas mitochondrial $\mathrm{Ca}_{\text {res }}$ occurs specifically at large MFBs.

\section{Downstream mechanisms for mitochondria-dependent PTP at MF synapses}

Growing body of evidence support that activation of PKC is required for PTP at many synapses in hippocampus and cerebellum (Alle et al., 2001; Brager et al., 2003; Beierlein et al., 2007). Previously, a new downstream target of PKC has been suggested as a mechanism for PTP in hippocampal cultured cells (Wierda et al., 2007). Although mitochondrial involvement in PTP remains to be investigated at these synapses, these studies suggest that PKCmediated PTP occurs more widely at central synapses than mitochondria-dependent PTP. Similar to PTP at large MFBs, we found that PTP at immature calyx of Held is mediated by mitochondria-dependent $\mathrm{Ca}_{\text {res }}$ (our unpublished observations), suggesting that mitochondrial involvement in PTP may be preferentially observed at large presynaptic terminals in CNS and raising a question whether mitochondria- and PKC-dependent PTP are expressed in a mutually exclusive manner at central synapses.

Although the key role of $\mathrm{Ca}_{\text {res }}$ has been demonstrated at $\mathrm{NMJs}$, downstream mechanisms underlying PTP are still elusive. It is widely accepted that simple summation of $\mathrm{Ca}_{\text {res }}$ is not sufficient to induce significant facilitation because of large difference in the amplitudes of residual $\left[\mathrm{Ca}^{2+}\right]$ and microdomain $\left[\mathrm{Ca}^{2+}\right]$. Given that GCs express a high concentration of calbindin-D28K (Müller et al., 2005), which buffers cytosolic $\mathrm{Ca}^{2+}$ fast sufficient to limit the size of a $\mathrm{Ca}^{2+}$ microdomain, it is of particular interest that partial saturation of endogenous $\mathrm{Ca}^{2+}$ buffers play a role in synaptic facilitation at mossy fiber synapses (Blatow et al., 2003). Recent simulation results predict that appreciable magnitude of facilitation occurs through buffer saturation within fairly narrow ranges of buffering parameters (Matveev et al., 2004). Therefore, it remains to be elucidated whether post-tetanic residual $\left[\mathrm{Ca}^{2+}\right]$ level is high enough to saturate calbindin and to induce PTP by the mechanism of buffer saturation. 


\section{Significance of PTP in hippocampal synaptic computation}

A previous electron microscopy study revealed that the crosssectional area of the large MFBs was $7 \mu \mathrm{m}^{2}$ on average at the end of the third postnatal week, when large MFBs display full morphological features of adult large MFBs (Amaral and Dent, 1981). The physical dimension of large MFBs is comparable with what we observed in the present study $\left(8.50 \pm 0.34 \mu \mathrm{m}^{2}\right)$. Even after the third postnatal week, large MFBs increase in size and complexity throughout life, especially in response to enriched environment (Galimberti et al., 2006). These changes may accompany an increased mitochondrial contribution to PTP at synapses of large MFBs.

Large MFBs are found at $\mathrm{MF} \rightarrow \mathrm{MC}$ and $\mathrm{MF} \rightarrow \mathrm{CA} 3$ pyramidal cells (CA3-PCs) synapses, both of which share the unique postsynaptic morphology of a thorny excrescence. Previously, $\mathrm{MF} \rightarrow \mathrm{MC}$ synapses were reported to exhibit short- and longterm synaptic plasticity, which is generally similar to the $\mathrm{MF} \rightarrow \mathrm{CA} 3$ pyramidal cell synapses (Lysetskiy et al., 2005). Furthermore, no electron microscopic difference was found between the large MFBs in the hilar region and those in the CA3 field (Amaral and Dent, 1981). Thus, it is plausible that mitochondriadependent $\mathrm{Ca}_{\text {res }}$ also occurs at large MFBs terminating onto CA3 pyramidal cell.

Mossy fiber synapses are unique in that they show a wide dynamic range of plasticity (Nicoll and Schmitz, 2006). The in vivo study has revealed that single spike in a GC is not sufficient but the train of spikes is required to discharge the target CA3-PC, suggesting that a synaptic facilitation is crucial for the detonator role of large MFBs (Henze et al., 2002). Facilitation of an MF synapse onto CA3-PCs accompanies profound increase in network inhibition because of overriding number of synaptic termination onto interneurons (Acsady et al., 1998; Mori et al., 2007). The network inhibition may limit the time window for integration of excitatory inputs in a CA3-PC by the mechanism of feedforward inhibition. Therefore, propagation of a neuronal spike from a GC into a CA3-PC heavily depends on the balance between direct excitatory MF input onto CA3-PCs and bisynaptic inhibitory input via feedforward inhibitory circuit. If the results of the present study can be extrapolated to MF synapses in CA3, it can be postulated that $\mathrm{PTP}$ at $\mathrm{MF} \rightarrow \mathrm{PC}$ and $\mathrm{MF} \rightarrow$ interneuron (IN) synapses in CA3 may occur by mechanisms of mitochondrial $\mathrm{Ca}^{2+}$ release and $\mathrm{PKC}$, respectively. Differential mechanisms of $\mathrm{PTP}$ at $\mathrm{MF} \rightarrow \mathrm{CA} 3-\mathrm{PC}$ and $\mathrm{MF} \rightarrow \mathrm{IN}$ may provide an important basis for studying network excitability in the hippocampal CA3 field.

\section{Appendix}

The single compartment model predicts mono-exponential decay of cytosolic $\left[\mathrm{Ca}^{2+}\right]_{\mathrm{i}}$ in response to $\mathrm{Ca}^{2+}$ influx evoked by a single AP (Helmchen et al., 1997; Lee et al., 2000). The model assumes the cytosolic space to be a single compartment whose $\mathrm{Ca}^{2+}$ extrusion rate is linear to cytosolic $\left[\mathrm{Ca}^{2+}\right]$ excursion from its resting level $\left(\Delta\left[\mathrm{Ca}^{2+}\right]_{i}\right)$ with a rate constant $\gamma$. The impulse response of this linear system is as follows:

$$
h(t)=A \times e^{-t / \tau} .
$$

By definition, the time integral of an input $\delta$ function, $\int \delta(t) d t$, or the increment of total $\mathrm{Ca}^{2+}$ concentration $\left(\Delta[\mathrm{Ca}]_{\mathrm{T}}\right)$ is unity. Assuming that incoming $\mathrm{Ca}^{2+}$ instantaneously equilibrates with $\mathrm{Ca}^{2+}$ buffers, the amplitude of the impulse response and decay rate constant are inversely proportional to the $\mathrm{Ca}^{2+}$-binding ratio $(\kappa)$. Thus,

$$
\begin{gathered}
A=1 /\left(1+\sum \kappa\right), \\
1 / \tau=\gamma /\left(1+\sum \kappa\right),
\end{gathered}
$$

where $\Sigma \kappa$ represents the sum of the $\mathrm{Ca}^{2+}$ binding ratios of all $\mathrm{Ca}^{2+}$ buffers in the cell (Lee et al., 2000).

The time-dependent change in $\Delta\left[\mathrm{Ca}^{2+}\right]_{\mathrm{i}}, y(t)$, of this linear system in response to an arbitrary time-dependent $\mathrm{Ca}^{2+}$ influx into the cytosol, $j(t)$, is given by a convolution of the input function $j(t)$ with the impulse response $h(t)$ :

$$
y(t)=j(t)^{\star} h(t)=\int_{0}^{t} j\left(t^{\prime}\right) \times A \times e^{\left(t-t^{\prime}\right) / \tau} d t^{\prime} .
$$

The $y(t)$ can be deconvolved as follows (Cohen et al., 1981; Neher and Sakaba, 2001):

$$
j(t)=\left(\frac{d y(t)}{d t}+\frac{y(t)}{\tau}\right) / A .
$$

Substitution of $\tau$ and A in equation A5 using equations A2 and A3 yields the following:

$$
j(t)=\frac{d y(t)}{d t}\left(1+\sum \kappa\right)+\gamma \times y(t) .
$$

The time integral of equation A6 from $t^{\prime}=0$ to $t$ yields the following:

$$
\begin{array}{r}
J(t) \equiv \int_{0}^{t} j\left(t^{\prime}\right) d t^{\prime}=-[y(0)-y(t)] \times\left(1+\sum \kappa\right)+\gamma \\
\times \int_{0}^{t} y\left(t^{\prime}\right) d t^{\prime}
\end{array}
$$

where $t>0$ and $y(0)>y(t)$. This equation gives the total amount of $\mathrm{Ca}^{2+}$ release (or influx) during a period $t$ after the start of the slow-decay phase. Using the relationship in equation $\mathrm{A} 3$, the above equation can be rewritten as follows:

$$
J(t) / \gamma=[y(t)-y(0)] \times \tau+\int_{0}^{t} y\left(t^{\prime}\right) d t^{\prime}
$$

The first term of equation A8 is the time integral, with a minus sign, of a CaT with monoexponential decay; the amplitude and time constant are $y(0)-y(t)$ and $\tau$, respectively. Because $y(\infty)=$ 0 , insertion of $t=\infty$ into equation A8 yields equation 4 .

\section{References}

Abbott LF, Regehr WG (2004) Synaptic computation. Nature 431:796-803. Acsady L, Kamondi A, Sik A, Freund T, Buzsaki G (1998) GABAergic cells are the major postsynaptic targets of mossy fibers in the rat hippocampus. J Neurosci 18:3386-3403.

Aiuchi T, Matsunaga M, Nakaya K, Nakamura Y (1985) Effects of probes of membrane potential on metabolism in synaptosomes. BBA 843:20-24.

Alle H, Jonas P, Geiger JRP (2001) PTP and LTP at a hippocampal mossy fiber-interneuron synapse. Proc Natl Acad Sci USA 98:14708-14713.

Amaral DG, Dent JA (1981) Development of the mossy fibers of the dentate gyrus: I. A light and electron microscopic study of the mossy fibers and their expansions. J Comp Neurol 195:51-86.

Beierlein M, Fioravante D, Regehr WG (2007) Differential expression of posttetanic potentiation and retrograde signaling mediate targetdependent short-term synaptic plasticity. Neuron 54:949-959. 
Bernardi P (1999) Mitochondrial transport of cations: channels, exchangers, and permeability transition. Physiol Rev 79:1127-1155.

Billups B, Forsythe ID (2002) Presynaptic mitochondrial calcium sequestration influences transmission at mammalian central synapses. J Neurosci 22:5840-5847.

Bischofberger J, Engel D, Frotscher M, Jonas P (2006) Timing and efficacy of transmitter release at mossy fiber synapses in the hippocampal network. Eur J Physiol 453:361-372.

Blatow M, Caputi A, Burnashev N, Monyer H, Rozov A (2003) $\mathrm{Ca}^{2+}$ buffer saturation underlies paired pulse facilitation in calbindin-D28kcontaining terminals. Neuron 38:79-88.

Brager DH, Cai X, Thompson SM (2003) Activity-dependent activation of presynaptic protein kinase $\mathrm{C}$ mediates post-tetanic potentiation. Nat Neurosci 6:551-552.

Claiborne BJ, Amaral DG, Cowan WM (1986) A light and electron microscopic analysis of the mossy fibers of the rat dentate gyrus. J Comp Neurol 246:435-458.

Cohen I, Van Der Kloot W, Attwell D (1981) The timing of channel opening during miniature end-plate currents. Brain Res 223:185-189.

Crompton M, Moser R, Ludi H, Carafoli E (1978) The interrelations between the transport of sodium and calcium in mitochondria of various mammalian tissues. Eur J Biochem 82:25-31.

David G, Barrett EF (2000) Stimulation-evoked increases in cytosolic $\left[\mathrm{Ca}^{2+}\right]$ in mouse motor nerve terminals are limited by mitochondrial uptake and are temperature-dependent. J Neurosci 20:7290-7296.

David G, Barrett JN, Barrett EF (1997) Stimulation-induced changes in $\left[\mathrm{Ca}^{2+}\right]$ in lizard motor nerve terminals. J Physiol (Lond) 504:83-96.

David G, Barrett JN, Barrett EF (1998) Evidence that mitochondria buffer physiological $\mathrm{Ca}^{2+}$ loads in lizard motor nerve terminals. J Physiol (Lond) 509:59-65.

Galimberti I, Gogolla N, Alberi S, Santos AF, Muller D, Caroni P (2006) Long-term rearrangements of hippocampal mossy fiber terminal connectivity in the adult regulated by experience. Neuron 50:749-763.

Garcia-Chacon LE, Nguyen KT, David G, Barrett EF (2006) Extrusion of $\mathrm{Ca}^{2+}$ from mouse motor terminal mitochondria via a $\mathrm{Na}^{+}-\mathrm{Ca}^{2+}$ exchanger increases post-tetanic evoked release. J Physiol (Lond) 574:663-675.

Habets RLP, Borst JGG (2005) Post-tetanic potentiation in the rat calyx of Held synapse. J Physiol (Lond) 564:173-187.

Hallermann S, Pawlu C, Jonas P, Heckmann M (2003) A large pool of releasable vesicles in a cortical glutamatergic synapse. Proc Natl Acad Sci USA 100:8975-8980.

Helmchen F, Borst JG, Sakmann B (1997) Calcium dynamics associated with a single action potential in a CNS presynaptic terminal. Biophys J 72:1458-1471.

Henze DA, Wittner L, Buzsaki G (2002) Single granule cells reliably discharge targets in the hippocampal CA3 network in vivo. Nat Neurosci 5:790-795.

Kamiya H, Zucker RS (1994) Residual $\mathrm{Ca}^{2+}$ and short-term synaptic plasticity. Nature 371:603-606.

Karadjov JS, Kudzina L, Zinchenko VP (1986) $\mathrm{TPP}^{+}$inhibits $\mathrm{Na}^{+}$. stimulated $\mathrm{Ca}^{2+}$ efflux from brain mitochondria. Cell Calcium 7:115-119.

Kim M-H, Lee S-h, Park KH, Ho W-K, Lee S-H (2003) Distribution of $\mathrm{K}^{+}$-dependent $\mathrm{Na}^{+} / \mathrm{Ca}^{2+}$ exchangers in the rat supraoptic magnocellular neuron is polarized to axon terminals. J Neurosci 23:11673-11680.

Kim MH, Korogod N, Schneggenburger R, Ho WK, Lee S-H (2005) Interplay between $\mathrm{Na}^{+} / \mathrm{Ca}^{2+}$ exchangers and mitochondria in $\mathrm{Ca}^{2+}$ clearance at the calyx of Held. J Neurosci 25:6057-6065.

Kirichok Y, Krapivinsky G, Clapham DE (2004) The mitochondrial calcium uniporter is a highly selective ion channel. Nature 427:360-364.

Koester HJ, Johnston D (2005) Target cell-dependent normalization of transmitter release at neocortical synapses. Science 308:863-866.

Korogod N, Lou X, Schneggenburger R (2005) Presynaptic $\mathrm{Ca}^{2+}$ requirements and developmental regulation of posttetanic potentiation at the calyx of Held. J Neurosci 25:5127-5137.

Lee SH, Rosenmund C, Schwaller B, Neher E (2000) Differences in $\mathrm{Ca}^{2+}$ buffering properties between excitatory and inhibitory hippocampal neurons from the rat. J Physiol (Lond) 525:405-418.

Lee SH, Sohn JW, Ahn SC, Park WS, Ho WK (2004) $\mathrm{Li}^{+}$enhances GABAergic inputs to granule cells in the rat hippocampal dentate gyrus. Neuropharmacology 46:638-646.
Lübke J, Frotscher M, Spruston N (1998) Specialized electrophysiological properties of anatomically identified neurons in the hilar region of the rat fascia dentata. J Neurophysiol 79:1518-1534.

Lysetskiy M, Földy C, Soltesz I (2005) Long- and short-term plasticity at mossy fiber synapses on mossy cells in the rat dentate gyrus. Hippocampus 15:691-696.

Maravall M, Mainen ZF, Sabatini BL, Svoboda K (2000) Estimating intracellular calcium concentrations and buffering without wavelength ratioing. Biophys J 78:2655-2667.

Matveev V, Zucker RS, Sherman A (2004) Facilitation through buffer saturation: constraints on endogenous buffering properties. Biophys 86:2691-2709.

Mori M, Gahwiler BH, Gerber U (2007) Recruitment of an inhibitory hippocampal network after bursting in a single granule cell. Proc Natl Acad Sci USA 104:7640-7645.

Mori M, Abegg MH, Gahwiler BH, Gerber U (2004) A frequencydependent switch from inhibition to excitation in a hippocampal unitary circuit. Nature 431:453-456.

Müller A, Kukley M, Stausberg P, Beck H, Muller W, Dietrich D (2005) Endogenous $\mathrm{Ca}^{2+}$ buffer concentration and $\mathrm{Ca}^{2+}$ microdomains in hippocampal neurons. J Neurosci 25:558-565.

Neher E, Augustine GJ (1992) Calcium gradients and buffers in bovine chromaffin cells. J Physiol (Lond) 450:273-301.

Neher E, Sakaba T (2001) Combining deconvolution and noise analysis for the estimation of transmitter release rates at the calyx of Held. J Neurosci 21:444-461.

Nicoll R, Schmitz D (2006) Synaptic plasticity at hippocampal mossy fibre synapses. Nat Rev Neurosci 6:863-876.

Pelkey KA, Topolnik L, Lacaille J-C, McBain CJ (2006) Compartmentalized $\mathrm{Ca}^{2+}$ channel regulation at divergent mossy-fiber release sites underlies target cell-dependent plasticity. Neuron 52:497-510.

Regehr WG (1997) Interplay between sodium and calcium dynamics in granule cell presynaptic terminals. Biophys J 73:2476-2488.

Regehr WG, Delaney KR, Tank DW (1994) The role of presynaptic calcium in short-term enhancement at the hippocampal mossy fiber synapse. J Neurosci 14:523-537.

Rozov A, Burnashev N, Sakmann B, Neher E (2001) Transmitter release modulation by intracellular $\mathrm{Ca}^{2+}$ buffers in facilitating and depressing nerve terminals of pyramidal cells in layer $2 / 3$ of the rat neocortex indicates a target cell-specific difference in presynaptic calcium dynamics. J Physiol (Lond) 531:807-826.

Sabatini BL, Oertner TG, Svoboda K (2002) The life cycle of $\mathrm{Ca}^{2+}$ ions in dendritic spines. Neuron 33:439-452.

Salin PA, Scanziani M, Malenka Robert C, Nicoll Roger A (1996) Distinct short-term plasticity at two excitatory synapses in the hippocampus. Proc Natl Acad Sci USA 93:13304-13309.

Storozhuk MV, Ivanova SY, Balaban PM, Kostyuk PG (2005) Possible role of mitochondria in posttetanic potentiation of GABAergic synaptic transmission in rat neocortical cell cultures. Synapse 58:45-52.

Suzuki S, Osanai M, Mitsumoto N, Akita T, Narita K, Kijima H, Kuba K (2002) $\mathrm{Ca}^{2+}$-dependent $\mathrm{Ca}^{2+}$ clearance via mitochondrial uptake and plasmalemmal extrusion in frog motor nerve terminals. J Neurophysiol 87:1816-1823.

Tang Yg, Zucker RS (1997) Mitochondrial involvement in post-tetanic potentiation of synaptic transmission. Neuron 18:483-491.

Toth K, McBain CJ (2000) Target-specific expression of pre- and postsynaptic mechanisms. J Physiol (Lond) 525:41-51.

Wierda KDB, Toonen RFG, de Wit H, Brussaard AB, Verhage M (2007) Interdependence of PKC-dependent and PKC-independent pathways for presynaptic plasticity. Neuron 54:275-290.

Wingrove DE, Gunter TE (1986) Kinetics of mitochondrial calcium transport. II. A kinetic description of the sodium-dependent calcium efflux mechanism of liver mitochondria and inhibition by ruthenium red and by tetraphenylphosphonium. J Biol Chem 261:15166-15171.

Zhong N, Beaumont V, Zucker RS (2001) Roles for mitochondrial and reverse mode $\mathrm{Na}^{+} / \mathrm{Ca}^{2+}$ exchange and the plasmalemma Ca ${ }^{2+}$ ATPase in post-tetanic potentiation at crayfish neuromuscular junctions. J Neurosci 21:9598-9607.

Zucker RS, Regehr WG (2002) Short-term synaptic plasticity. Annu Rev Physiol 64:355-405. 